\title{
Laboratory Leaching Tests to Investigate Mobilisation and Recovery of Metals from Geothermal Reservoirs
}

\author{
Máté Osvald ${ }^{1},{ }^{1}$ Andrew D. Kilpatrick, ${ }^{2}$ Christopher A. Rochelle, ${ }^{2}$ János Szanyi, ${ }^{1}$ \\ Tamás Medgyes, ${ }^{1}$ and Balázs Kóbor ${ }^{1}$ \\ ${ }^{1}$ University of Szeged, Department of Mineralogy, Geochemistry and Petrology, Egyetem u. 2, Szeged H-6722, Hungary \\ ${ }^{2}$ British Geological Survey, Nicker Hill, Keyworth, Nottingham NG12 5GG, UK \\ Correspondence should be addressed to Máté Osvald; osimate@geo.u-szeged.hu
}

Received 27 July 2018; Accepted 24 September 2018; Published 13 December 2018

Guest Editor: Domenico Montanari

Copyright (C) 2018 Máté Osvald et al. This is an open access article distributed under the Creative Commons Attribution License, which permits unrestricted use, distribution, and reproduction in any medium, provided the original work is properly cited.

\begin{abstract}
The H2020 project "Combined Heat, Power and Metal extraction" (CHPM2030) aims at developing a novel technology which combines geothermal energy utilisation with the extraction of metals in a single interlinked process. In order to improve the economics of geothermal-based energy production, the project investigates possible technologies for the exploitation of metalbearing geological formations with geothermal potential at depths of 3-4 km or deeper. In this way, the coproduction of energy and metals would be possible and could be optimized according to market demands in the future. This technology could allow the mining of deep ore bodies, particularly for critical metals, alongside power production, while minimizing environmental impact and costs. In this paper, we describe laboratory leaching experiments aimed at quantifying the relative rates and magnitudes of metal release and seeing how these vary with different fluids. Specific size fractions $(250-500 \mu \mathrm{m})$ of ground mineralised rock samples were investigated under various pressures and temperatures up to $250 \mathrm{bar}$ and $250^{\circ} \mathrm{C}$. Initial experiments involved testing a variety of potential leaching fluids with various mineralised samples for a relatively long time (up to $720 \mathrm{~h}$ ) in batch reactors in order to assess leaching effectiveness. Selected fluids were used in a flow-through reactor with shorter contact time $(0.6 \mathrm{~h})$. To ensure possible application in a real geothermal reservoir, a range of fluids were considered, from dilute mineral acid to relatively environmentally benign fluids, such as deionised water and acetic acid. The main findings of the study include fast reaction time, meaning that steady-state fluid compositions were reached in the first few hours of reaction and enhanced mobilisation of $\mathrm{Ca}, \mathrm{Cd}, \mathrm{Mn}, \mathrm{Pb}, \mathrm{S}, \mathrm{Si}$, and $\mathrm{Zn}$. Some critical elements, such as $\mathrm{Co}$, $\mathrm{Sr}$, and $\mathrm{W}$, were also found in notable concentrations during fluid-rock interactions. However, the amount of these useful elements released is much less compared to the common elements found, which include $\mathrm{Al}, \mathrm{Ca}, \mathrm{Fe}, \mathrm{K}, \mathrm{Mg}, \mathrm{Mn}, \mathrm{Na}, \mathrm{Pb}, \mathrm{S}, \mathrm{Si}$, and $\mathrm{Zn}$. Even though concentrations of dissolved metals increased during the tests, some remained low, and this may present technical challenges for metal extraction. Future efforts will work toward attaining actual fluids from depth to more tightly constrain the effect of parameters such as salinity, which will also influence metal solubility.
\end{abstract}

\section{Introduction}

The strategic objective of the CHPM2030 project is to develop a novel technological solution (combined heat, power, and metal extraction from ultradeep ore-bearing rocks), to make geothermal energy more attractive, and to reduce Europe's dependence on the import of metals and fossil fuels [1].
The idea of using geothermal brines for mineral extraction has existed for decades. One key element of interest is lithium [2-4], but a wide spectrum of elements that may be suitable for extraction is present in geothermal reservoirs and fluids $[5,6]$.

Current demand for metals is driving an expansion in mining operations aided by scientific and technical advances in, for example, the use of robotics, nano-mining, laser 


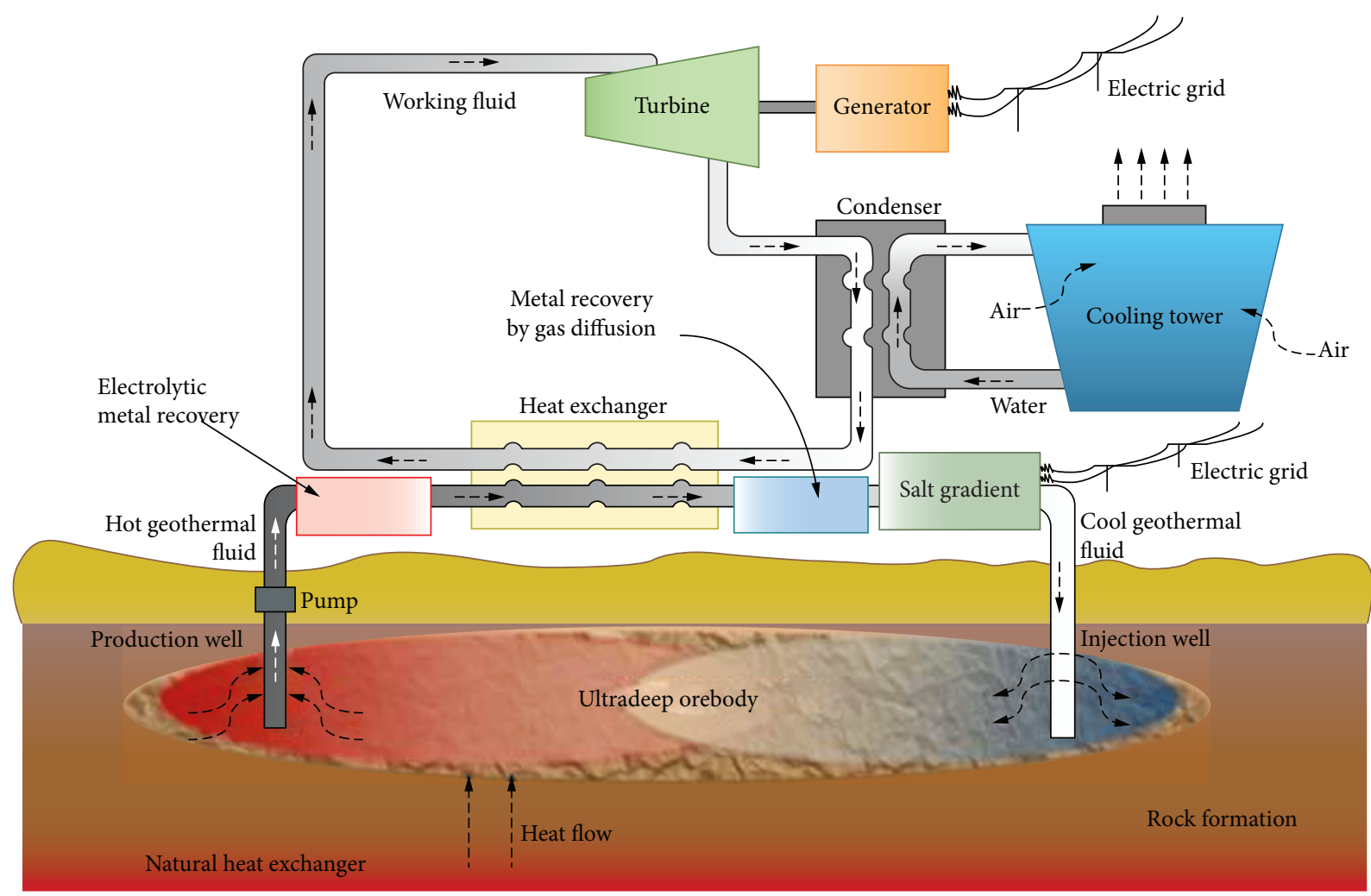

FIGURE 1: Schematic representation of the CHPM concept. The information presented in this report relates to the release of metals from the "ultradeep orebody" and into the recirculating geothermal fluid.

mining $[7,8]$, etc. These developing technologies reduce the exposure of miners to hazardous underground environments and make possible the selective transport of valuable metals to the surface rather than moving large amounts of material which will eventually go to waste.

In the envisioned CHPM technology, an enhanced or engineered geothermal system (EGS) is established within a metal-bearing geological formation at depths of $3-4 \mathrm{~km}$ or more (Figure 1). Based on geological and hydrogeological settings, EGS could be hydrothermal or petrothermal (a hot dry rock (HDR) system) [9]. The concept involves the manipulation of a theoretical petrothermal system such that the coproduction of energy and metals will be possible [10]. Through experiments at the laboratory scale, we have investigated the leaching potential of various fluids and whether such enhancement of geothermal systems can make them more attractive economically, i.e., whether metals can be leached from orebodies in economic concentrations over prolonged periods, and if leaching might increase the system's performance over time (through, for example, silicate dissolution and permeability enhancement), negating or reducing the use of more common methods of reservoir stimulation.

A key aspect of the CHPM2030 concept is that metals can be transported in solution from mineralised structures at depth to surface infrastructure where they can be extracted (Figure 1). Based on current technology, which often relies on exchange or adsorption processes, the extraction process will be more effective with higher dissolved concentrations of metals [11] and hence with faster rates of dissolution of metal-bearing minerals. However, too large a dissolved load may lead to problems of precipitation within production boreholes or surface infrastructure, and hence, it increases maintenance needs and costs. Thus, there is a need to balance the potential for increased revenue generation from recovering more metals against potential increased costs resulting from increased maintenance operations. There is also a need to consider the wider physical environment in which the systems will need to operate as well as issues of public acceptance [12]. This includes being mindful of environmental considerations and the carefully controlled use of additives that are relatively environmentally benign.

Factors underpinning the above aspects are the rates and magnitudes of metal release, and laboratory experiments simulating in situ conditions are a useful way to provide well-constrained data to help understand these. Such experiments also allow us to test different fluid compositions in order to ascertain if there are specific additives that may improve the metal recovery process [13].

Our approach has been to work initially at lower temperatures with a focus on a few mineralised samples (mainly on material from Cornwall, southwest England) in order to investigate the leaching potential of various fluids. Here, we present results from experiments using samples of mineralisation from Cornwall reacted with deionised water, acetic acid, and a mixture of hydrochloric and nitric acid. Samples from the Banatitic Magmatic and Metallogenetic Belt in Romania (BMMB Masca-Cacova Ierii) and Hungary (Rudabánya and Recsk) were also tested with deionised water and acetic acid. These fluids have been chosen to represent the scale from very benign (deionised water) to more aggressive 
TABLE 1: Major geological and mineral properties of the samples.

\begin{tabular}{|c|c|c|c|}
\hline Sample ID & Sample locality & Geological setting & $\begin{array}{l}\text { Summary of bulk mineralogy } \\
\text { (as determined by XRD) }\end{array}$ \\
\hline HTLMix & $\begin{array}{l}\text { Herodsfoot, } \\
\text { SW England }\end{array}$ & $\begin{array}{l}\text { Baked sediments with partial } \\
\text { quartz vein }\end{array}$ & $\begin{array}{l}87 \% \text { quartz, } 5 \% \text { muscovite, } 2 \% \text { dolomite, } 5 \% \text { galena, } \\
\text { minor albite, chlorite, pyrite, and sphalerite }\end{array}$ \\
\hline HTL315 & $\begin{array}{l}\text { South Caradon, } \\
\text { SW England }\end{array}$ & $\begin{array}{l}\text { Mainstage mineralisation } \\
\text { associated with granite bodies }\end{array}$ & $\begin{array}{c}70 \% \text { quartz, } 7 \% \text { schorl, } 5 \% \text { chlorite, } 2 \% \text { calcite, } \\
10 \% \text { pyrite, } 5 \% \text { arseonpyrite, and minor greigite and biotite }\end{array}$ \\
\hline HTL319 & $\begin{array}{l}\text { Cligga Head, } \\
\text { SW England }\end{array}$ & $\begin{array}{l}\text { Tin-tungsten mineralisation } \\
\text { associated with granite bodies }\end{array}$ & $\begin{array}{c}88 \% \text { quartz, } 2 \% \text { muscovite, } 3 \% \text { cassiterite, } \\
3 \% \text { columbite, and } 4 \% \text { ferberite }\end{array}$ \\
\hline HTL321 & $\begin{array}{l}\text { Masca-Cocovaleni, } \\
\text { Romania }\end{array}$ & Mineralised skarn country rock & $\begin{array}{l}22 \% \text { dolomite, } 49 \% \text { pyrite, } 27 \% \text { magnetite, } \\
\text { minor quartz, calcite, and barite }\end{array}$ \\
\hline HTL322 & $\begin{array}{l}\text { Rudabánya, } \\
\text { NE Hungary }\end{array}$ & $\begin{array}{l}\text { Carbonate hosted lead-zinc } \\
\text { mineralisation }\end{array}$ & $\begin{array}{c}8 \% \text { quartz, } 2 \% \text { calcite, } 68 \% \text { magnesite, } 6 \% \text { cerussite, } \\
1 \% \text { sphalerite, } 1 \% \text { columbite, } 11 \% \text { barite, } \\
2 \% \text { magnetite, and minor dolomite }\end{array}$ \\
\hline HTL324 & Recsk, NE Hungary & Porphyry sulphide polymetallic ore & $\begin{array}{l}74 \% \text { quartz, } 5 \% \text { calcite, } 9 \% \text { pyrite, } 11 \% \text { magnetite, } \\
\text { minor albite, dolomite, and sphalerite }\end{array}$ \\
\hline
\end{tabular}

but still reasonably acceptable ( $0.1 \mathrm{M}$ acetic acid or 'vinegar') and to very aggressive and environmentally unacceptable mineral acid.

Experiments were run using both batch equipment, where materials are reacted in a closed system, and from which samples are withdrawn regularly, and also flow-through equipment, where fluid is passed once through the system.

\section{Materials}

The solids used in the experimental work are detailed in Table 1. Samples generally consist of either massive mineralisation or mineralised material together with some surrounding country rock.

All samples were repeatedly crushed in a tempered steel jaw crusher to obtain a powdered fraction of $<500 \mu \mathrm{m}$. This fraction was then sieved to produce a $500-250 \mu \mathrm{m}$ fraction, which was used for the experimental and analytical work. This fraction was cleaned to remove fines and surface impurities, by repeated rinsing in acetone, until the supernatant ran clear. These "washed" samples were then oven dried at $30^{\circ} \mathrm{C}$.

Solid samples will be referred to by their unique threedigit identifier throughout this report. Samples collected by British Geological Survey were from sites in South West England and labelled HTL315, HTL319, and HTLMix which is a mixed sample from materials representative of a mineralised quartz vein (containing galena, sphalerite, and some chalcopyrite) found at Herodsfoot, southwest England. The mixture was used to provide more representative "bulk" mineralogy for use in experiments. HTL321 originates from a skarn deposit in the BMMB Masca-Cacova Ierii in Romania which is a magnetite deposit also enriched in sulphides with visible chalcopyrite. HTL322 is from Rudabánya, Hungary, from a Mississippi Valley Type (MVT) deposit. The sample is characterised by banded baritic lead ore from a metasomatic deposit hosted by limestone; galena grains in dark bands can be recognized with coarse-grained white barite lenses and fine-grained limonitic matrix. HTL324 from Recsk, Hungary, represents porphyry mineralisation sampled from an intrusion related to porphyry copper deposits and includes a breccia with sulphide matrix and veins [14]. Starting materials were characterised using Xray diffraction for bulk mineralogy and BET (BrunauerEmmett-Teller) analysis for surface area.

Details of the solid samples, including their sampling location, geological setting, and a summary of their bulk composition, as determined by XRD, can be found in Table 1. All samples were collected from the surface, generally from mine dumps or rockfalls adjacent to exposures. Efforts were made to ensure that the material used for the experiments was as pristine as possible, i.e., materials at or near (within $\sim 10 \mathrm{~cm}$ ) weathered surfaces were avoided. A variety of solutions were used in the experiments in order to test their relative potential for liberation of metals from ore-bearing deposits. Most of these were created using one or two reagents dissolved or diluted to the desired concentration. The fluids used in the experiments reported here as well as the temperature/pressure conditions of the experiments using various solids are summarised in Table 2.

\section{Method}

3.1. Batch Experiments. Two different methods were used for the batch experiments, which are chosen according to the experimental conditions (i.e., pressure and temperature) required. Initial experiments were carried out at atmospheric pressure, using high-density polyethylene (HDPE) bottles fixed into a rotating mixing assembly. Solid samples were carefully weighed and added to the appropriate fluid in a 40: 1 fluid : rock ratio. The relatively high fluid to rock ratio was chosen to meet fluid sampling requirements while minimising changes in reaction rate due to relative changes in fluid : rock ratio due to sampling. The experimental "charge" in these experiments consisted of an accurately known amount of granulated rock sample (around $5 \mathrm{~g}$ ) together with $200 \mathrm{ml}$ of reactant solution. The tops of the HDPE bottles were securely tightened, the vessels were arranged symmetrically on the mixer, and the entire assembly was placed into a thermostatically-controlled fan-assisted oven. When 
TABLE 2: Summary of experimental materials and conditions used.

\begin{tabular}{|c|c|c|c|c|c|c|c|c|c|}
\hline \multirow{2}{*}{$\begin{array}{l}\text { Solvent } \\
\text { Sample } \\
\text { ID }\end{array}$} & \multicolumn{3}{|c|}{ Deionised water } & \multicolumn{3}{|c|}{$0.1 \mathrm{M}$ acetic acid } & \multirow{2}{*}{$\begin{array}{c}0.01 \mathrm{M} \mathrm{HCl}, \\
0.003 \mathrm{M} \mathrm{HNO} 3 \\
100^{\circ} \mathrm{C}, 200 \mathrm{bar} \\
\text { batch }\end{array}$} & \multicolumn{2}{|c|}{$\begin{array}{c}0.1 \mathrm{M} \mathrm{HCl}, 0.03 \mathrm{M} \\
\mathrm{HNO} 3\end{array}$} \\
\hline & $\begin{array}{l}70^{\circ} \mathrm{C}, \\
1 \text { bar } \\
\text { batch }\end{array}$ & $\begin{array}{c}100^{\circ} \mathrm{C}, \\
200 \mathrm{bar} \\
\text { batch }\end{array}$ & $\begin{array}{l}200^{\circ} \mathrm{C}, 250 \mathrm{bar} \\
\text { flow-through }\end{array}$ & $\begin{array}{l}70^{\circ} \mathrm{C} \text {, } \\
1 \text { bar } \\
\text { batch }\end{array}$ & $\begin{array}{c}150^{\circ} \mathrm{C} \text {, } \\
200 \text { bar } \\
\text { batch }\end{array}$ & $\begin{array}{c}250^{\circ} \mathrm{C}, 250 \mathrm{bar} \\
\text { flow-through }\end{array}$ & & $\begin{array}{c}100^{\circ} \mathrm{C}, \\
200 \text { bar } \\
\text { batch }\end{array}$ & $\begin{array}{c}200^{\circ} \mathrm{C} \text {, } \\
200 \text { bar } \\
\text { batch }\end{array}$ \\
\hline HTLMix & $\checkmark$ & & & $\checkmark$ & $\checkmark$ & $\checkmark$ & $\checkmark$ & $\checkmark$ & $\checkmark$ \\
\hline HTL315 & $\checkmark$ & $\checkmark$ & & $\checkmark$ & & $\checkmark$ & & & \\
\hline HTL319 & $\checkmark$ & & & $\checkmark$ & & $\checkmark$ & & & \\
\hline HTL321 & & & $\checkmark$ & & & $\checkmark$ & $\checkmark$ & & \\
\hline HTL322 & & & $\checkmark$ & & & $\checkmark$ & & & \\
\hline HTL324 & & & $\checkmark$ & & & $\checkmark$ & $\checkmark$ & & \\
\hline
\end{tabular}

running, the mixer turned at approximately six revolutions per minute-enough to ensure good mixing between solid and solution without causing too much mechanical damage to the solid grains.

Higher temperature and pressure experiments utilised titanium batch reactors inside thermostatically-controlled fan-assisted ovens $[15,16]$. The basic layout of the batch reactors used is shown schematically in Figure 2. Viton Orings are used between the vessel body and vessel head to prevent loss of pressure. A large retaining ring is screwed onto the top of the vessel to keep the vessel body and vessel head together when pressurised. This equipment was used for the experiments at $100^{\circ} \mathrm{C}, 150^{\circ} \mathrm{C}$, and $200^{\circ} \mathrm{C}$.

Loading the vessel consisted of adding accurately known amounts of granulated rock (approximately $8.75 \mathrm{~g}$ ) and synthetic groundwater or other leaching solution $(350 \mathrm{ml})$ plus a magnetic stirrer bead in the experiments carried out below $200^{\circ} \mathrm{C}$. The head of the reaction vessel was then pushed on, and the retaining ring securely screwed down. The headspace of the vessel was flushed with nitrogen prior to pressurisation. A titanium dip tube (and associated valve), fitted with a PTFE filter assembly, was added to each vessel.

To minimise mechanical damage to the solid, the stirrer bead was both held in a small cage and only activated for approximately 2 minutes in every 4 hours. For the experiments conducted at $200^{\circ} \mathrm{C}$, the stirrer assembly and stirrer bead, as well as the filter assembly, had to be removed, and instead, the vessels were periodically agitated by hand (on average about once per day). Nitrogen was used to pressurise these batch experiments with experimental pressure being controlled via an ISCO $360 \mathrm{D}$ syringe pump. The $\mathrm{N}_{2}$ used was classified as "oxygen free" (99.998\% pure).

At the end of each experiment, as much of the solution as possible was removed prior to cooling and depressurisation of the vessel. Once well below $100^{\circ} \mathrm{C}$ (i.e., the boiling point of the leachate being used), the vessel was slowly depressurised, dismantled, and reacted rock grains recovered for subsequent analysis. Batch experiments were run for around 600-1000 hours.

3.2. Flow-through Experiments. Leaching processes were also investigated under continuous flow conditions using a flowthrough reactor (Figure 3). The reaction took place in a stainless steel high-pressure liquid chromatography (HPLC) column $250 \mathrm{~mm}$ in length and with an inner diameter of $21.2 \mathrm{~mm}$. The pressure in the column was maintained by an Ecom Kappa 10 Single-Plunger HPLC pump. A $50 \mathrm{~cm}$ stainless steel capillary and a fluid back-pressure regulator were fitted at the outflow of the column. The length of this tubing was used to allow outflowing fluid to cool to below $90^{\circ} \mathrm{C}$ before being depressurised. Heating bands were attached to the column and controlled by a thermostat (WH-1435D PID digital thermostat with $\pm 1^{\circ} \mathrm{C}$ control regulation). This high-pressure high-temperature device was loaded with approximately $150 \mathrm{~g}$ of the rock sample and operated at a temperature of approximately $250^{\circ} \mathrm{C}$ and a pressure of 250 bar. These parameters correspond to depths of around $2.5-3 \mathrm{~km}$ in an average geothermal field $[9,17]$. During the experiments, the flow rate in the reactor was $0.5 \mathrm{ml}$ per minute, which resulted in a contact time between the fluid and rock of 30-50 minutes, allowing the collection of sufficient sample volumes for chemical analyses.

3.3. Sampling and Analysis. For sampling, the experiments carried out using the rotating shaker setup; rotation was stopped, and the bottles were removed from the assembly one at a time to minimise any cooling following removal from the oven. Upon removal, each bottle was unsealed, and a sample was removed using a polyethylene syringe and subsequently filtered using a $0.2 \mu \mathrm{m}$ nylon syringe filter prior to subsampling for analyses.

For experiments carried out using titanium vessels, a valve on top of the vessel (attached to an internal titanium sampling tube) was opened to a syringe attached to the valve via a length of polyetheretherketone (PEEK) tubing. An accurately known quantity (typically $1-5 \mathrm{ml}$ ) of fluid was allowed to flow into the syringe in order to flush the sample tube, valve, and tubing. This syringe was removed and discarded. A second syringe was then attached and used to withdraw an accurately known amount (approximately $10 \mathrm{ml}$ ) of fluid. This sample was subsequently filtered using a $0.2 \mu \mathrm{m}$ nylon syringe filter.

Once a sample of filtered fluid was obtained, each was split into several sub-samples for ion chromatography (IC), inductively coupled mass spectrometry (ICP-MS), alkalinity (carried out by titration against sulphuric acid), and reduced iron (carried out colorimetrically using ultraviolet spectrometry) analyses as well as analysis of $\mathrm{pH}$ and Eh. Subsamples 

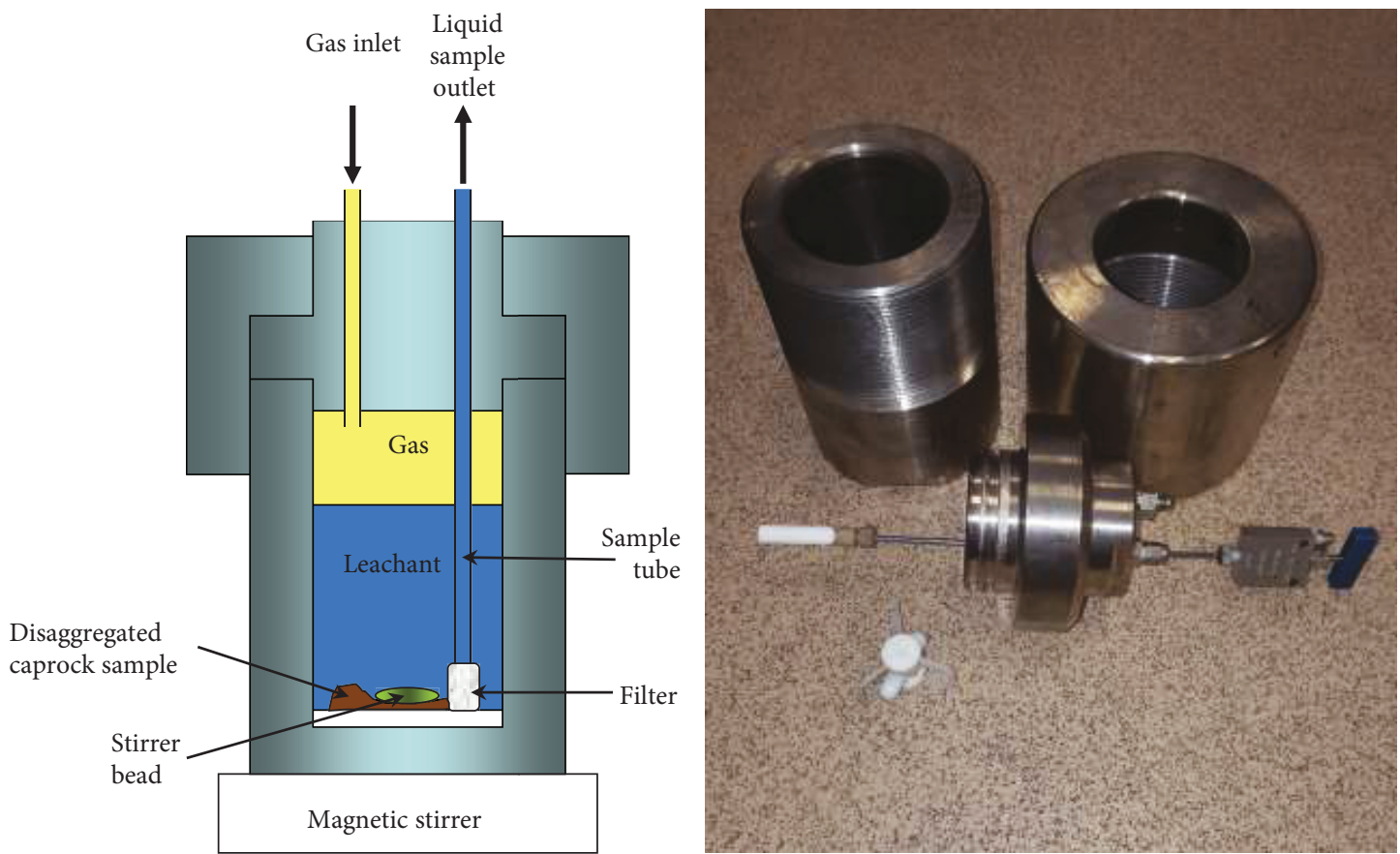

FIGURE 2: Schematic diagram and photograph of a titanium batch reactor.

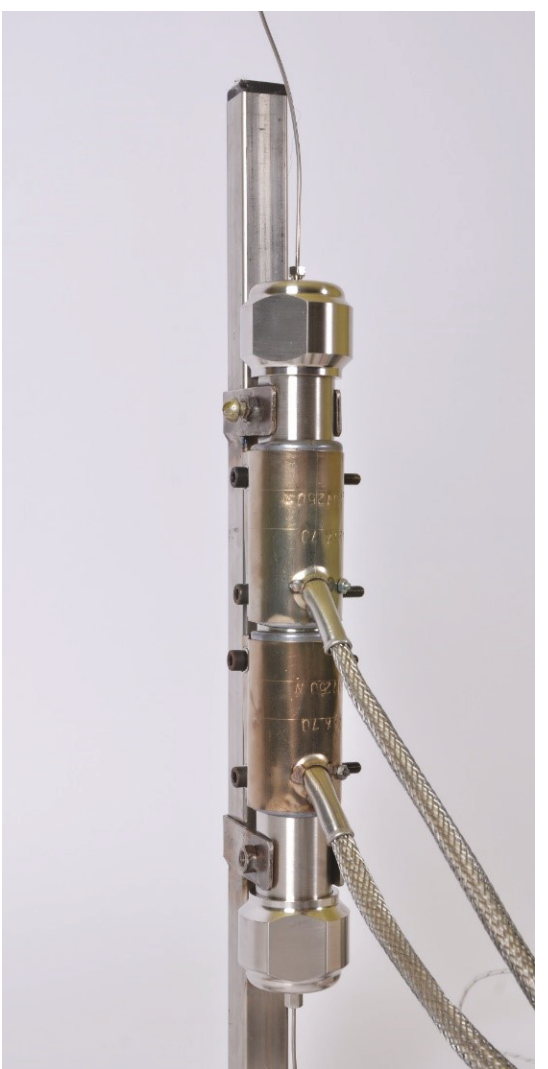

(a)

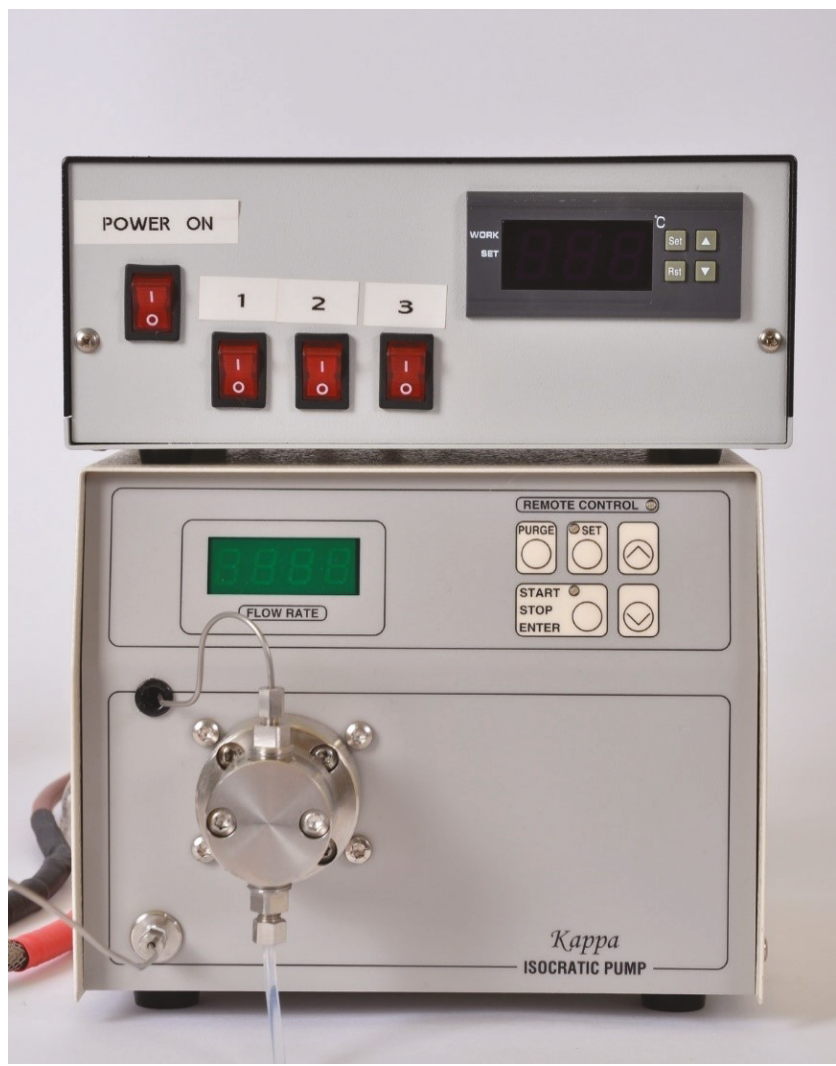

(b)

Figure 3: Flow-through reactor (a) and temperature control on top of the HPLC pump used (b). 


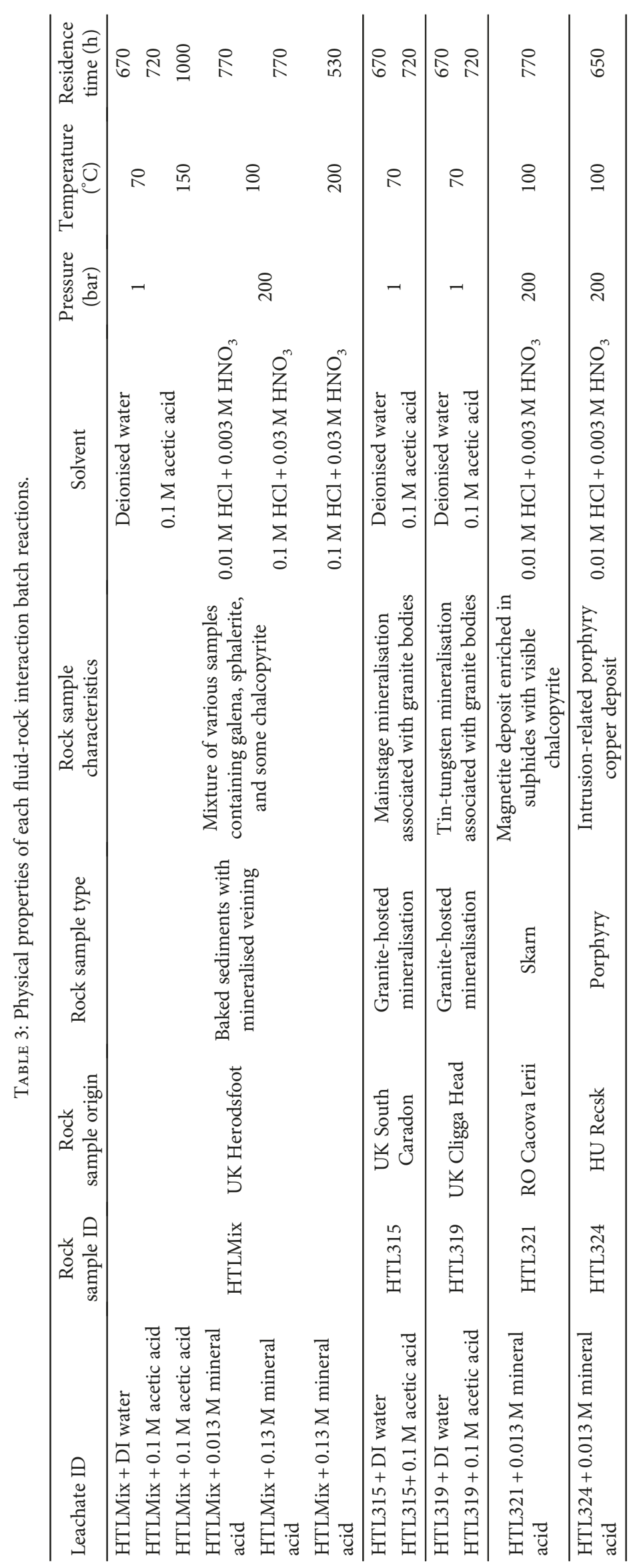


TABLE 4: Concentration of the "at risk" elements in each leachate from the batch reaction.

\begin{tabular}{|c|c|c|c|c|c|c|c|c|c|}
\hline $\begin{array}{l}\text { Element } \\
\text { Sample }\end{array}$ & $\begin{array}{c}\mathrm{Ag} \\
\mathrm{PPB}\end{array}$ & $\begin{array}{l}\text { Co } \\
\text { PPB }\end{array}$ & $\begin{array}{c}\mathrm{Ga} \\
\mathrm{PPB}\end{array}$ & $\begin{array}{l}\text { Mo } \\
\text { PPB }\end{array}$ & $\begin{array}{c}\mathrm{Sb} \\
\mathrm{PPB}\end{array}$ & $\begin{array}{c}\mathrm{Sr} \\
\mathrm{PPB}\end{array}$ & $\begin{array}{c}\mathrm{V} \\
\mathrm{PPB}\end{array}$ & $\begin{array}{l}\text { W } \\
\mathrm{PPB}\end{array}$ & $\begin{array}{c}\text { Total "at risk" } \\
\text { PPB }\end{array}$ \\
\hline HTLMix + DI water & $*$ & $*$ & $*$ & $*$ & 116.41 & 51.30 & ${ }^{*}$ & ${ }^{*}$ & 167.71 \\
\hline HTLMix $+0.1 \mathrm{M}$ acetic acid & * & 77.29 & 17.15 & * & 20.41 & 92.04 & * & 67.67 & 274.56 \\
\hline HTLMix $+0.1 \mathrm{M}$ acetic acid $200^{\circ} \mathrm{C}$ & $*$ & 26.48 & 4.00 & 1.04 & 656.28 & 141.60 & * & $*$ & 829.40 \\
\hline HTLMix + 0.013 M mineral acid & * & 3.76 & $*$ & 2.64 & 32.10 & 84.80 & * & 0.24 & 123.54 \\
\hline $\mathrm{HTLMix}+0.13 \mathrm{M}$ mineral acid $100^{\circ} \mathrm{C}$ & * & 159.07 & 12.00 & 17.48 & 3.49 & 149.20 & * & 0.28 & 341.52 \\
\hline HTLMix $+0.13 \mathrm{M}$ mineral acid $200^{\circ} \mathrm{C}$ & * & 979.95 & 8.00 & 176.00 & 7100.00 & 220.00 & * & 7.98 & 8491.92 \\
\hline HTL315 + DI water & * & 1001.28 & $*$ & $*$ & 71.93 & $*$ & * & $*$ & 1073.21 \\
\hline HTL315 + 0.1 M acetic acid & * & 1069.75 & * & * & 90.06 & * & * & 91.59 & 1251.40 \\
\hline HTL319 + DI water & * & $*$ & * & * & 2.41 & * & * & 181.83 & 184.24 \\
\hline HTL319 + 0.1 M acetic acid & * & * & * & $*$ & $*$ & $*$ & * & 128.04 & 128.04 \\
\hline HTL321 + 0.013 M mineral acid & * & 11.64 & $*$ & 2.60 & 43.51 & 101.20 & * & $*$ & 158.95 \\
\hline HTL324 + 0.013 M mineral acid & * & 5.52 & * & 0.44 & 0.16 & 58.40 & * & * & 64.52 \\
\hline
\end{tabular}

*: concentration was under the detection limit.

for ICP-MS analysis were diluted using deionised water and acidified using $\mathrm{HNO}_{3}$. Subsamples for alkalinity and ion chromatography (IC) analyses were diluted using deionised water. Subsamples for analysis of reduced iron were diluted and prepared for analysis using deionised water and 2,2-bipyridyl solution.

At the end of each experiment, as much of the fluid phase was removed as possible to minimise the formation of unwanted precipitates during cooling and depressurisation. The vessels were then cooled as rapidly as possible to below $80^{\circ} \mathrm{C}$ and then depressurised. After the opening of the reaction vessels, any residual fluid was sampled (and then subsampled and preserved as per samples described above) to allow characterisation of any chemical changes in the system during depressurisation and cooling. The reacted solids were removed from the vessel, a subsample of which was rinsed using acetone, and then oven dried at $30^{\circ} \mathrm{C}$.

For quantitative whole-rock X-ray diffraction (XRD) analysis, $>5 \mathrm{~g}$ samples of the starting solids were ball-milled and then micronized underwater to a fine powder $(<10 \mu \mathrm{m})$. XRD analysis was carried out using a PANalytical X'Pert Pro series diffractometer equipped with a cobalt-target tube and operated at $45 \mathrm{kV}$ and $40 \mathrm{~mA}$. Derivation of quantitative mineralogical data was accomplished by using the least squares fitting process applying the Rietveld refinement technique [18]. A subsample of the crushed starting solids was also dissolved using hydrofluoric acid digestion, and the resulting liquid was analysed using ICP-MS as per the fluid samples from the experiments.

\section{Results}

4.1. Batch Experiments. Batch experiments were conducted using deionised water, acetic acid (in $0.1 \mathrm{M}$ concentration), and mineral acid (a mixture of $0.13 \mathrm{M} \mathrm{HCl}$ and $0.013 \mathrm{M}$ $\mathrm{HNO}_{3}$ ) on the range of samples HTLMix, HTL315, HTL319, HTL321, and HTL 324 at $70^{\circ} \mathrm{C}, 100^{\circ} \mathrm{C}, 150^{\circ} \mathrm{C}$, and $200^{\circ} \mathrm{C}$ under 1 bar $\left(70^{\circ} \mathrm{C}\right.$ experiments only) and 200 bar pressure (Table 3 ). In this study, the elements appearing in the highest concentration were $\mathrm{Al}, \mathrm{B}, \mathrm{Ba}, \mathrm{Ca}, \mathrm{Cd}, \mathrm{Cr}, \mathrm{Cu}, \mathrm{Fe}, \mathrm{K}$, $\mathrm{Mg}, \mathrm{Mn}, \mathrm{Na}, \mathrm{Ni}, \mathrm{Pb}, \mathrm{Rb}, \mathrm{S}, \mathrm{Si}$, and $\mathrm{Zn}$. The economic value of these elements is debatable, due to limited utility or wide availability, and these elements are here referred to as "common" elements. Elements with higher value but appearing in lower concentrations, such as Ag, Co, Ga, Mo, Sb, Sr, V, and $\mathrm{W}$ elements, were selected as desirable and referred to as "at risk" elements in this paper based on the evaluation by European Commission et al. [1]. Data about the composition of samples from batch reactions, on which the following figures are based, can be found in Tables 4 and 5 . To illustrate results from analyses, spider plots were used, where individual elements are arranged in a ring around a central point representing zero concentration of all the elements. Thus, concentrations increase away from the centre of the plot (in this study on a logarithmic scale).

4.1.1. Leaching Tests Using Deionised Water as Solvent. Leaching experiments were carried out using deionised water on UK samples HTL315, HTL319, and HTLMix at $70^{\circ} \mathrm{C}$. The total concentration of "common" elements found in the leachate shown in Figure 4 corresponds to approximately $70 \mathrm{ppm}$ in the case of HTL315, $5.4 \mathrm{ppm}$ in the case of HTL319, and 29 ppm in the case of HTLMix. In HTL315, Fe and Si were the elements detected in higher concentration, accounting for $58 \%$ and $24 \%$ of the total "common" elemental concentration, respectively. In HTL319, Si was the most abundant element, accounting for $96 \%$ of the total "common" elemental concentration. For the leachate produced by reaction with HTLMix, Mg was the most abundant element, with $\mathrm{K}$ and $\mathrm{Si}$ were also detected, accounting for $67 \%, 16 \%$, and $15 \%$ of the total "common" elemental concentrations, respectively.

Reaction at $70^{\circ} \mathrm{C}$ temperature under 1 bar pressure with HTL315, HTL319, and HTLMix resulted in the mobilisation of approximately $1070 \mathrm{ppb}, 180 \mathrm{ppb}$, and $170 \mathrm{ppb}$ of the 


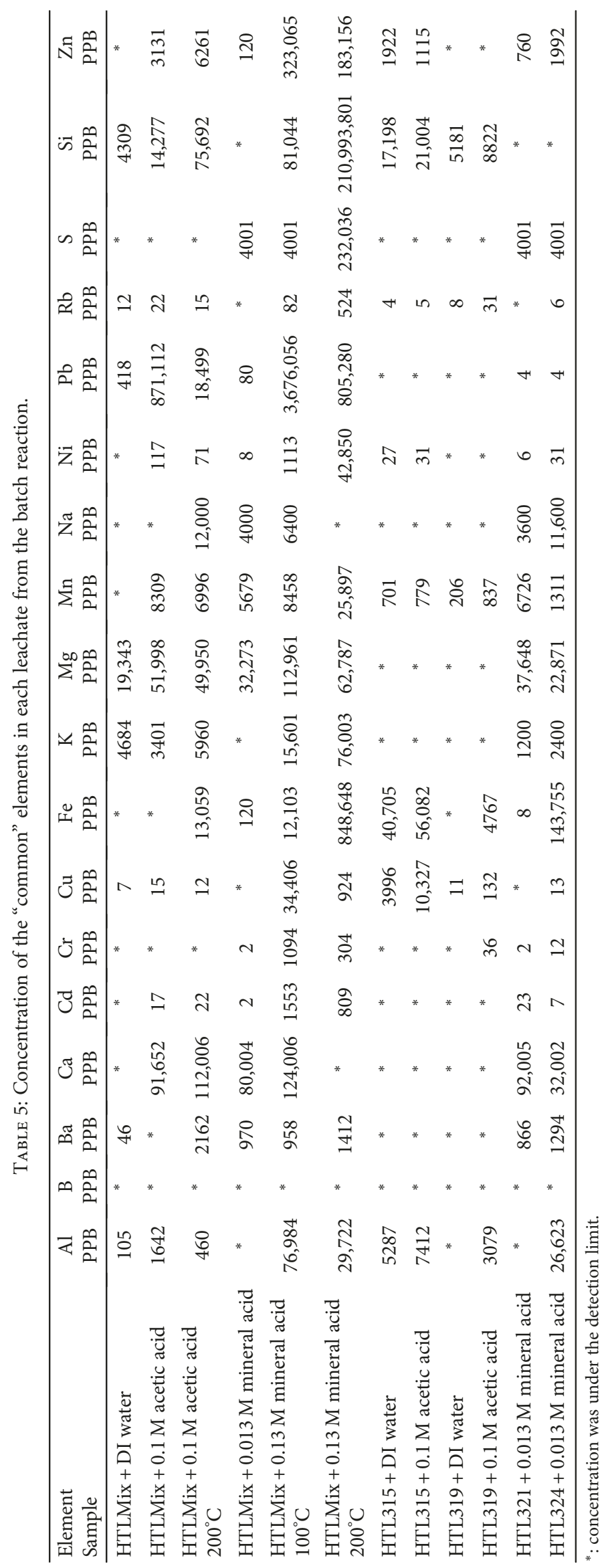



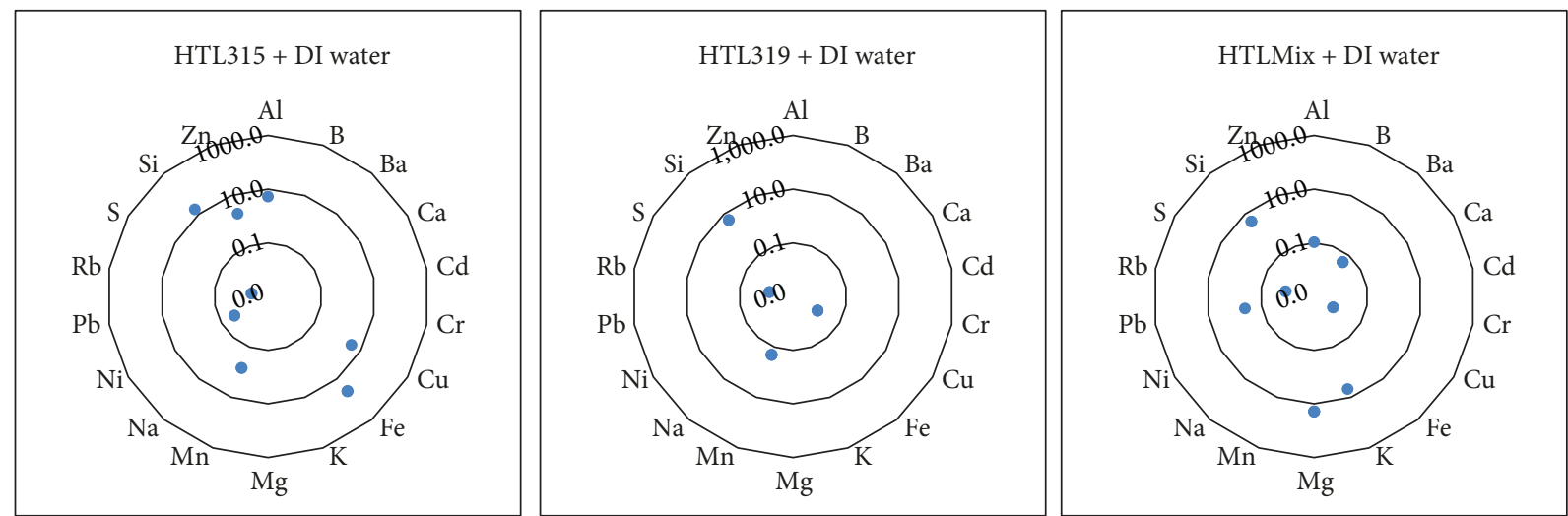

FIGURE 4: Common elemental composition (in ppm) of each leachate reacted with deionised water at $70^{\circ} \mathrm{C}$ temperature under 1 bar pressure in batch rotating shakers after 670 hours (absence of data points reflects concentrations below the limits of detection).
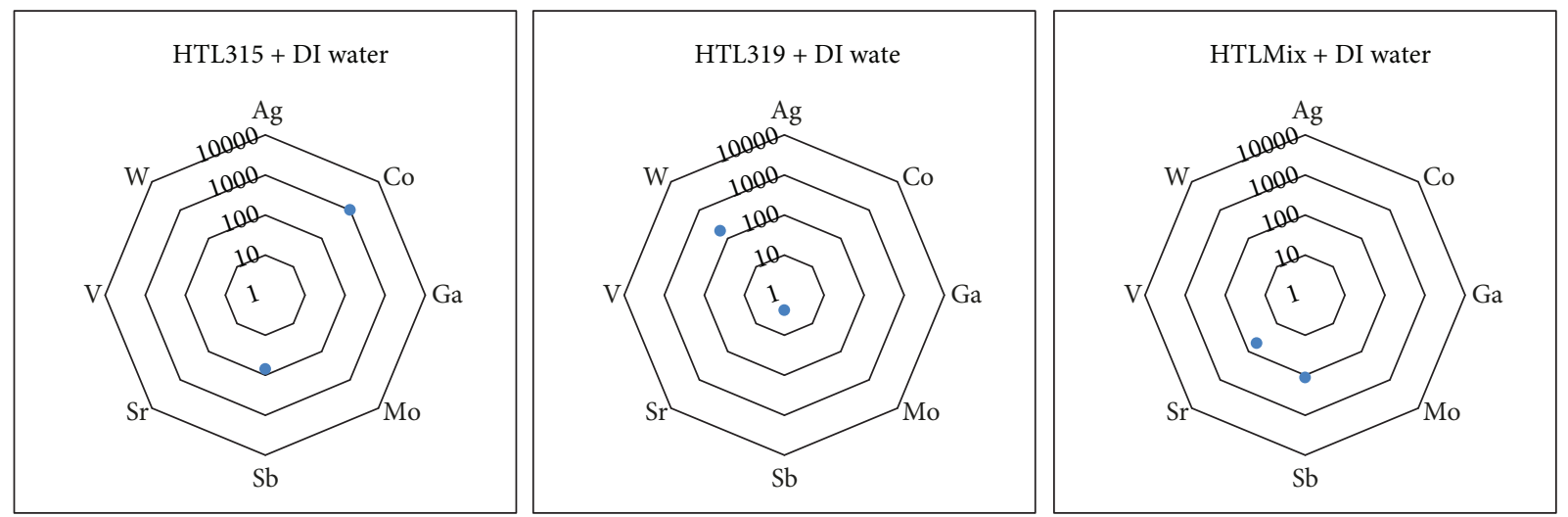

Figure 5: Concentration (in ppb) of the "at risk" elements in each sample reacted with deionised water at $70^{\circ} \mathrm{C}$ temperature under 1 bar pressure in batch rotating shakers after 670 hours (absence of data points reflects concentrations below the limits of detection).
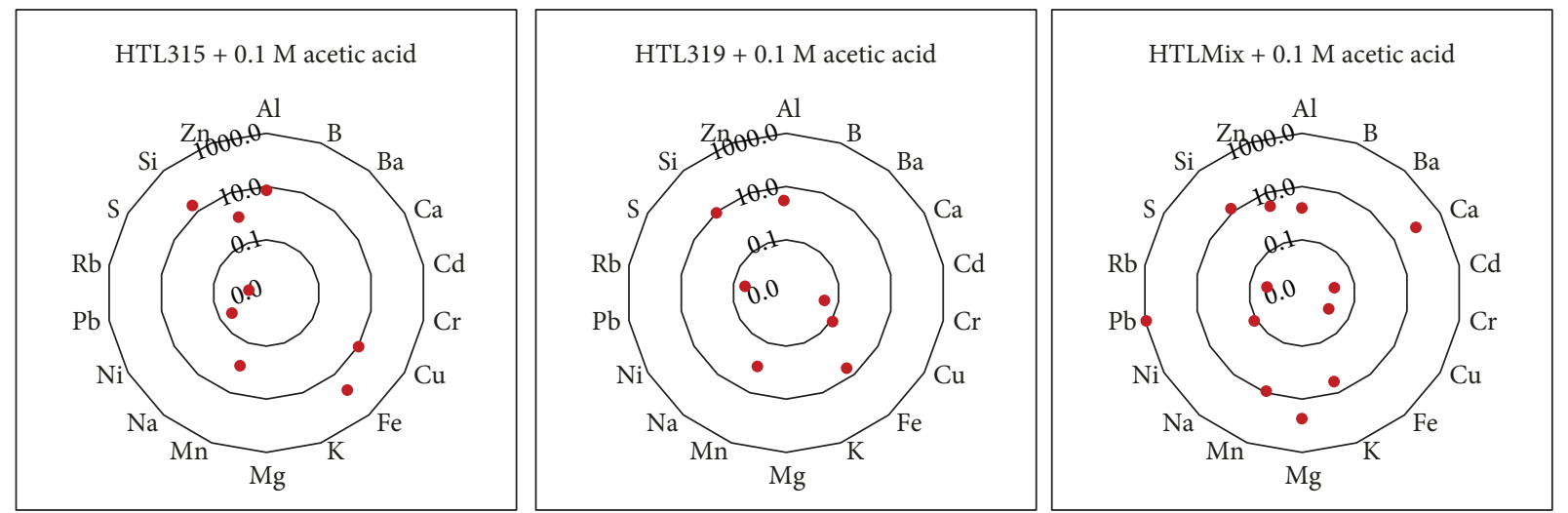

FIgURE 6: Elemental composition (in ppm) of each leachate reacted with $0.1 \mathrm{M}$ acetic acid at $70^{\circ} \mathrm{C}$ temperature under 1 bar pressure in batch rotating shakers after 720 hours (absence of data points reflects concentrations below the limits of detection).

selected "at risk" elements, respectively. Of these elements, $\mathrm{Co}, \mathrm{W}$, and $\mathrm{Sb}$ were detected at the highest concentrations (Figure 5).

4.1.2. Leaching Tests Using Acetic Acid as Solvent. The total concentration of "common" elements in the final sample taken at $70^{\circ} \mathrm{C}$, shown in Figure 6, corresponds to approximately $100 \mathrm{ppm}$ in the case of HTL315, $18 \mathrm{ppm}$ in the case of HTL319, and $1050 \mathrm{ppm}$ in the case of HTLMix. In HTL315, Fe and Si were the elements with the highest concentration, yielding $58 \%$ and $22 \%$ of the total "common" elements. In HTL319, Si was the most dominant among the 

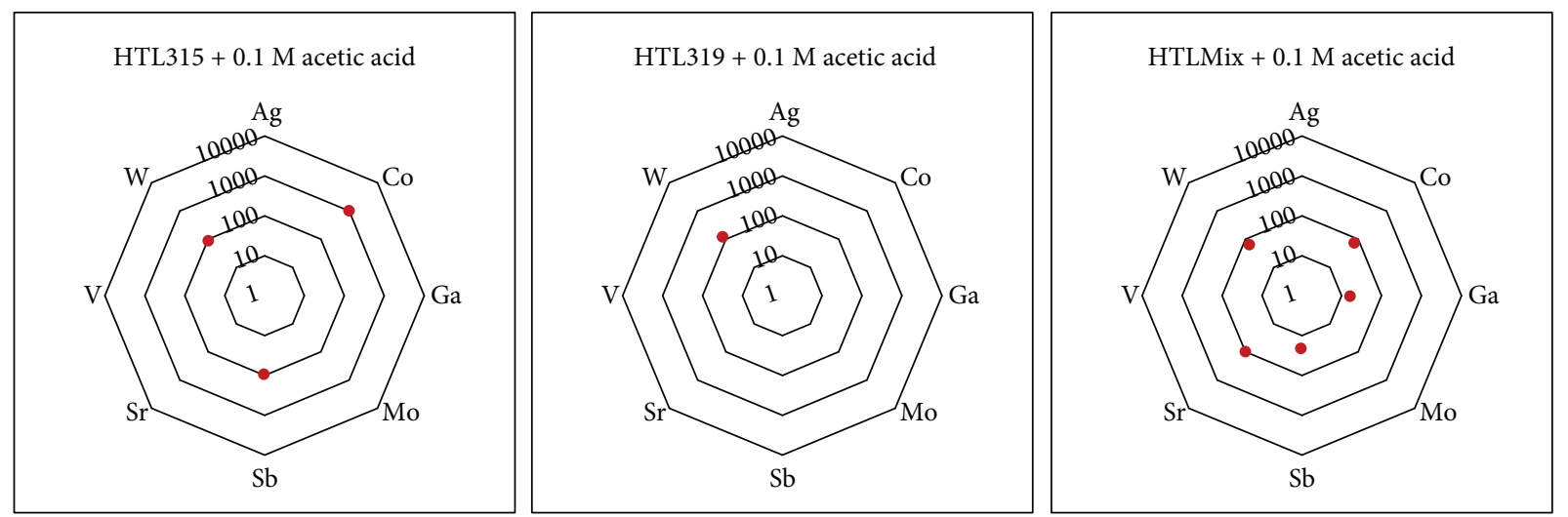

Figure 7: Concentration (in ppb) of the "at risk" elements in each sample reacted with $0.1 \mathrm{M}$ acetic acid at $70^{\circ} \mathrm{C}$ temperature under 1 bar pressure in batch rotating shakers (absence of data points reflects concentrations below the limits of detection).

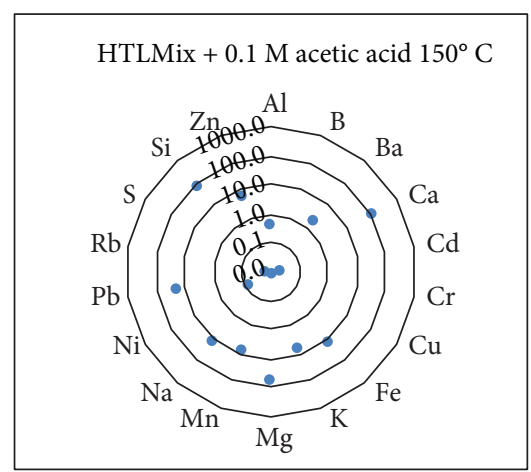

(a)

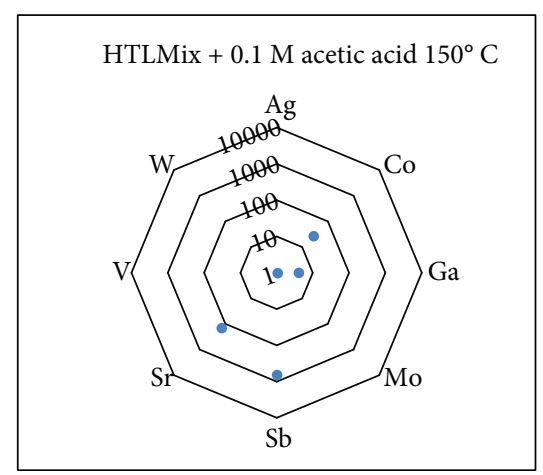

(b)

Figure 8: Concentration of the "common" ((a) in ppm) and "at risk" ((b) in ppb) elements obtained from HTLMix at $150^{\circ} \mathrm{C}$ temperature under 200 bar pressure in Ti batch vessel after 1000 hours (absence of data points reflects concentrations below the limits of detection).
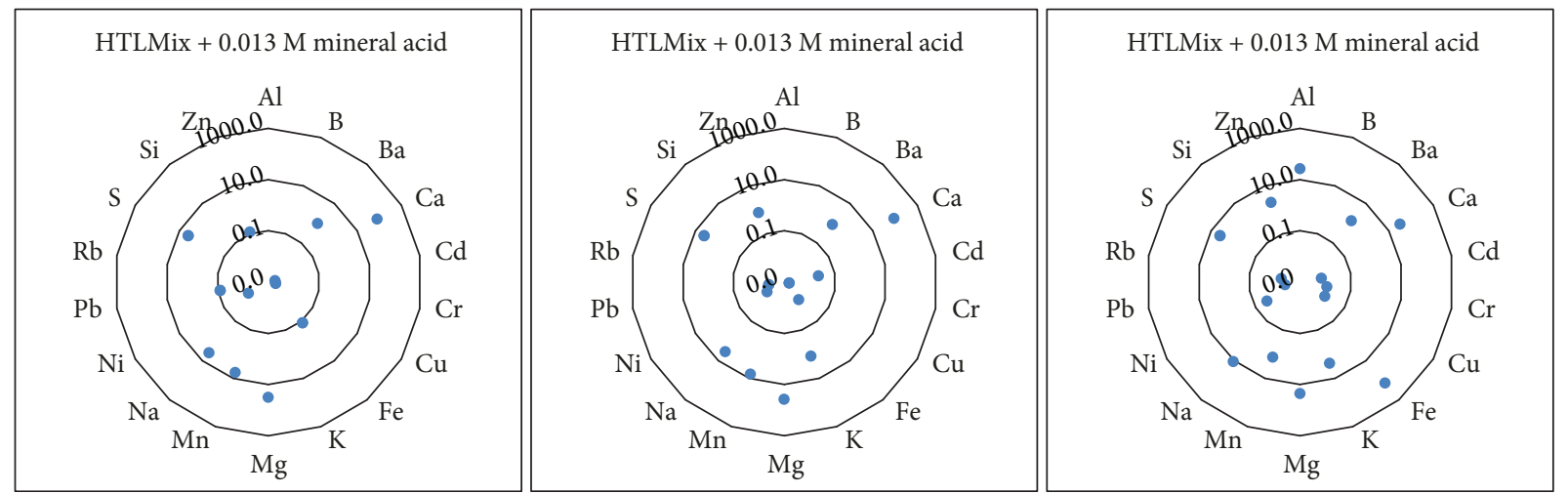

FIGURE 9: Elemental composition (in ppm) of each leachate reacted with the mixture of $0.01 \mathrm{M} \mathrm{HCl}$ and $0.003 \mathrm{M} \mathrm{HNO}_{3}$ at $100^{\circ} \mathrm{C}$ temperature under 200 bar pressure in Ti batch reactors (absence of data points reflects concentrations below the limits of detection).

"common" elements, accounting for $50 \%$ of the total dissolved concentration. In the case of HTLMix, large amounts of lead were leached, with concentrations of $870 \mathrm{ppm} \mathrm{Pb}$ in the final sample, accounting for $83 \%$ of the total concentration of "common" elements observed.

Reaction with $0.1 \mathrm{M}$ acetic acid at $70^{\circ} \mathrm{C}$ temperature under 1 bar pressure resulted in leached concentrations of approximately $1250 \mathrm{ppb}$ of the selected "at risk" elements in the case of HTL315, $130 \mathrm{ppb}$ in the case of HTL319, and $280 \mathrm{ppb}$ in the case of HTLMix (Figure 7). The most efficient mobilisation was in the case of HTL315; in this sample, Co was leached at a concentration of up to $1070 \mathrm{ppb}$. Tungsten was also detected in every leachate though at lower concentrations. 

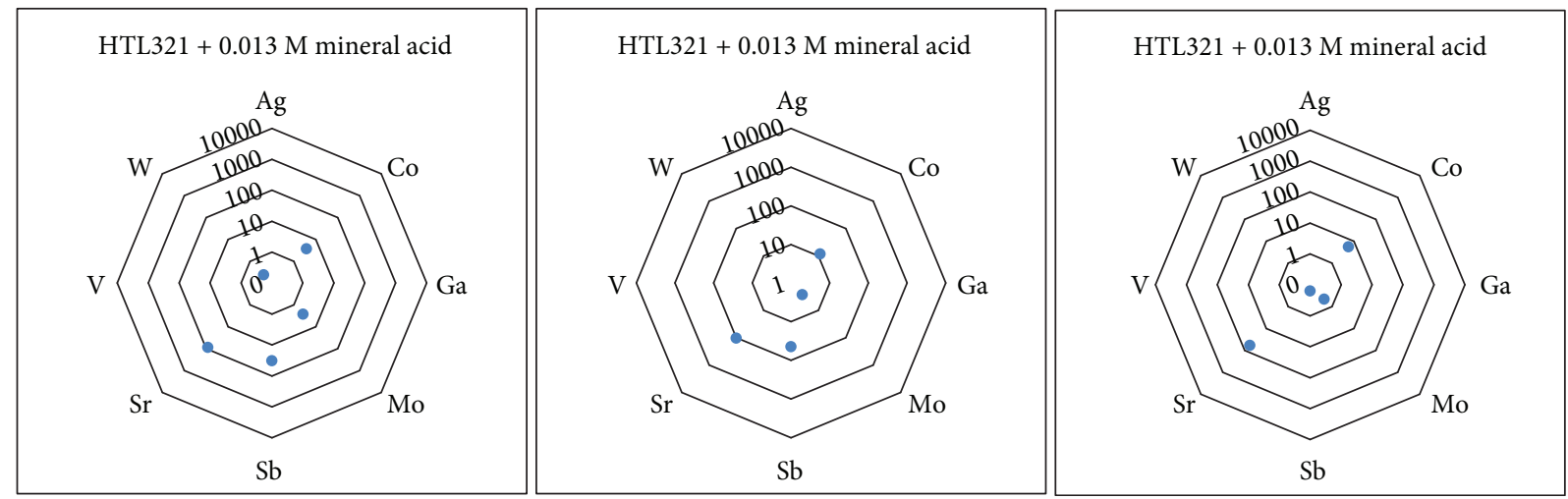

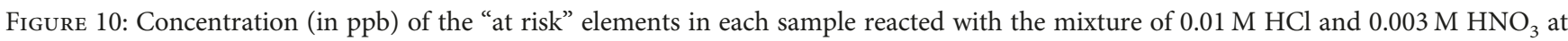
$100^{\circ} \mathrm{C}$ temperature under 200 bar pressure in Ti batch reactors after 770 hours (absence of data points reflects concentrations below the limits of detection).
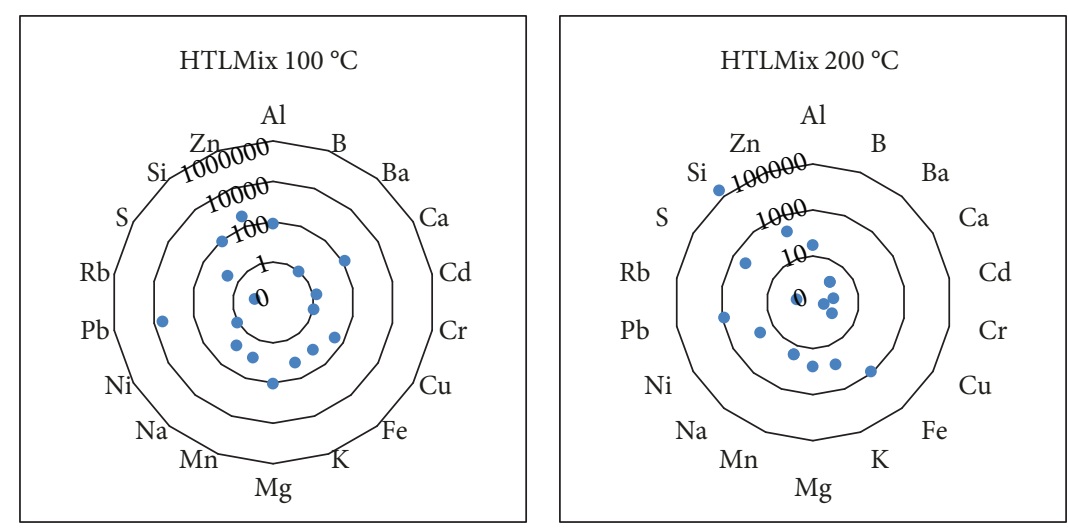

Figure 11: Elemental composition (in ppm) of HTLMix reacted with the mixture of $0.1 \mathrm{M} \mathrm{HCl}$ and $0.03 \mathrm{M} \mathrm{HNO}_{3}$ at $100^{\circ} \mathrm{C}$ and $200^{\circ} \mathrm{C}$ temperature under 200 bar pressure in Ti batch reactors after 770 hours and 530 hours, respectively.
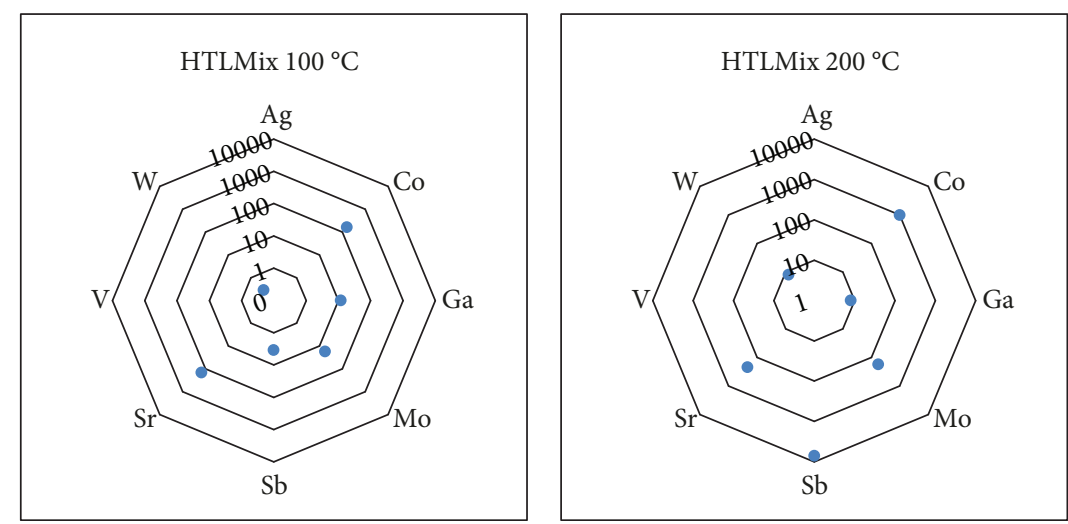

Figure 12: Concentration (in ppb) of the "at risk" elements in HTLMix reacted with the mixture of $0.1 \mathrm{M} \mathrm{HCl}^{\mathrm{H}} \mathrm{and} 0.03 \mathrm{M} \mathrm{HNO}^{3}$ at $100^{\circ} \mathrm{C}$ and $200^{\circ} \mathrm{C}$ temperature under 200 bar pressure in Ti batch reactors after 770 hours and 530 hours, respectively (absence of data points reflects concentrations below the limits of detection).

HTLMix was also leached using $0.1 \mathrm{M}$ acetic acid at $150^{\circ} \mathrm{C}$ temperature under 200 bar pressure. Figure 8 shows the concentrations of the selected "common" and "at risk" elements. The total concentrations of "common" and "at risk" elements mobilised were $300 \mathrm{ppm}$ and $830 \mathrm{ppb}$, respectively. $\mathrm{Ca}, \mathrm{Si}$, and $\mathrm{Pb}$ had the highest abundance amongst the "common" elements, constituting $37 \%, 25 \%$, and $6 \%$ of the total "common" elements leached, respectively. Sb, Sr, and Co were the most important "at risk" elements leached, constituting $79 \%, 17 \%$, and $3 \%$ of the total, respectively.

4.1.3. Leaching Tests Using Mineral Acid as Solvent. Leaching in Ti batch reactors using the mixture of $0.01 \mathrm{M}$ hydrochloric acid and $0.003 \mathrm{M}$ nitric acid was conducted at $100^{\circ} \mathrm{C}$ 


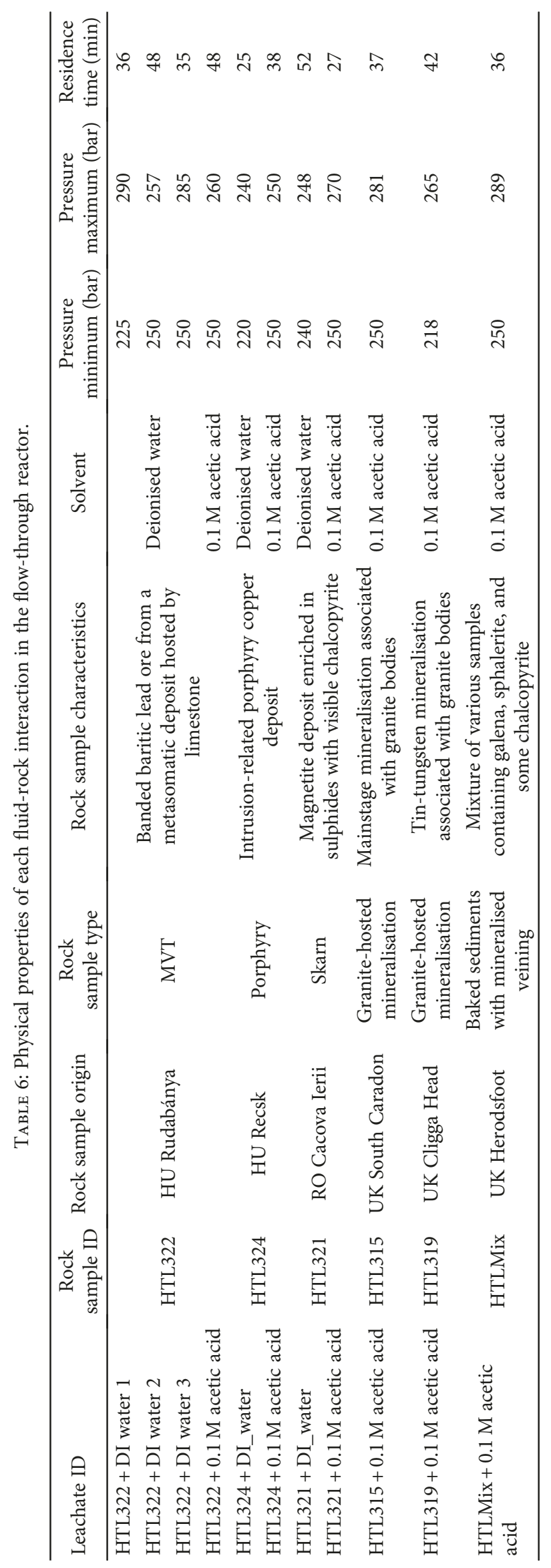


TABLE 7: Concentration of the "at risk" elements in each leachate from the flow-through reaction.

\begin{tabular}{|c|c|c|c|c|c|c|c|c|c|}
\hline $\begin{array}{l}\text { Element } \\
\text { Sample }\end{array}$ & $\begin{array}{c}\mathrm{Ag} \\
\mathrm{PPB}\end{array}$ & $\begin{array}{l}\text { Co } \\
\mathrm{PPB}\end{array}$ & $\begin{array}{c}\mathrm{Ga} \\
\mathrm{PPB}\end{array}$ & $\begin{array}{l}\text { Mo } \\
\text { PPB }\end{array}$ & $\begin{array}{l}\mathrm{Sb} \\
\mathrm{PPB}\end{array}$ & $\begin{array}{l}\mathrm{Sr} \\
\mathrm{PPB}\end{array}$ & $\begin{array}{c}\mathrm{V} \\
\mathrm{PPB}\end{array}$ & $\begin{array}{l}\text { W } \\
\text { PPB }\end{array}$ & $\begin{array}{c}\text { Total 'at risk' } \\
\text { PPB }\end{array}$ \\
\hline HTL322 + DI water 1 & * & 4.24 & ${ }^{*}$ & 0.6 & 19.45 & 844.57 & * & 0.19 & 869.05 \\
\hline HTL322 + DI water 2 & * & 2.77 & * & 0.6 & 15.81 & 660.15 & * & 0.07 & 679.40 \\
\hline HTL322 + DI water 3 & * & 2.02 & * & 0.5 & 65.22 & 489.79 & * & 0.05 & 557.58 \\
\hline HTL322 + 0.1 M acetic acid & * & 0.81 & * & 8.6 & 91.66 & 414.46 & * & 0.23 & 515.76 \\
\hline HTL324 + DI_water & 0.09 & 0.28 & * & 3.8 & 18.75 & 377.31 & 0.3 & 1.06 & 401.59 \\
\hline HTL324 + 0.1 M acetic acid & $*$ & $*$ & * & $*$ & * & 2837.00 & $*$ & $*$ & 2837.00 \\
\hline HTL321 + DI_water & $*$ & * & * & $*$ & * & 1526.00 & * & $*$ & 1526.00 \\
\hline HTL321 + 0.1 M acetic acid & * & $*$ & * & $*$ & $*$ & 1094.00 & * & * & 1094.00 \\
\hline HTL315 $+0.1 \mathrm{M}$ acetic acid & * & 209.29 & * & * & $*$ & 8.38 & 10 & * & 227.67 \\
\hline HTL319+0.1 M acetic acid & 90 & 9.2927 & $*$ & $*$ & 440 & 95.15 & $*$ & 470 & 1104.45 \\
\hline HTLMix $+0.1 \mathrm{M}$ acetic acid & 20 & 94.967 & $*$ & * & * & 918.33 & * & $*$ & 1033.30 \\
\hline
\end{tabular}

*: concentration was under the detection limit.

temperature under 200 bar pressure. The total concentration of "common" elements leached in the final sample, shown in Figure 9, was approximately 130 ppm in the case of HTLMix, $150 \mathrm{ppm}$ in the case of HTL321, and $250 \mathrm{ppm}$ in the case of HTL324. In the HTLMix leachate, $\mathrm{Ca}$ and $\mathrm{Mg}$ were detected in the highest concentration, constituting 63\% and 25\% of the total "common" elements, respectively. In this sample, $\mathrm{Mn}, \mathrm{Na}$, and $\mathrm{S}$ were also found at notable concentrations. In the leachate reacted with HTL321, Ca and Mg were also the most abundant elements, constituting $63 \%$ and $26 \%$ of the total "common" elements leached, respectively. $\mathrm{K}, \mathrm{Mn}$, $\mathrm{Ma}$, and $\mathrm{S}$ were also detected in lower but potentially recoverable concentrations in this sample. In the leachate reacted with HTL324, Fe was found in the highest concentration, constituting $58 \%$ of the total "common" elements leached. $\mathrm{Al}, \mathrm{Ca}, \mathrm{Mg}$, and $\mathrm{Zn}$ were also found in concentrations of 27 ppm, 32 ppm, 23 ppm, and 2 ppm, respectively.

Reaction with the mixture of $0.01 \mathrm{M}$ hydrochloric acid and $0.003 \mathrm{M}$ nitric acid at $100^{\circ} \mathrm{C}$ under 200 bar pressure resulted in leachate concentrations of approximately $125 \mathrm{ppb}$ of the selected "at risk" elements in the case of HTLMix, $160 \mathrm{ppb}$ in the case of HTL321, and $65 \mathrm{ppb}$ in the case of HTL324 (Figure 10). In these samples, Co, Mo, Sb, and $\mathrm{Sr}$ were detected, of which $\mathrm{Sb}$ had the highest concentrations in all three samples.

HTLMix was also leached using a higher concentration (0.1 $\mathrm{M}$ hydrochloric acid and $0.03 \mathrm{M}$ nitric acid), at $100^{\circ} \mathrm{C}$ and $200^{\circ} \mathrm{C}$, under 200 bar pressure. Figure 11 shows the concentrations of the "common" elements in each leachate. The total concentration of "common" elements leached was approximately $4480 \mathrm{ppm}$ at $100^{\circ} \mathrm{C}$ (770 hours) and $213,000 \mathrm{ppm}$ at $200^{\circ} \mathrm{C}$ (530 hours). In the case of reaction at $100^{\circ} \mathrm{C}$, the most abundant element leached was $\mathrm{Pb}$, which was found at a concentration of $3680 \mathrm{ppm}$ in the leachate. At $200^{\circ} \mathrm{C}, \mathrm{Si}, \mathrm{Fe}$, and $\mathrm{Pb}$ were the most abundant elements at $211000 \mathrm{ppm}, 850 \mathrm{ppm}$, and $805 \mathrm{ppm}$ concentration, respectively.

Reaction with the $0.13 \mathrm{M}$ mineral acid solution at $100^{\circ} \mathrm{C}$ and $200^{\circ} \mathrm{C}$ temperature under 200 bar pressure resulted in concentrations of approximately $340 \mathrm{ppb}$ and $8500 \mathrm{ppb}$ of the selected "at risk" elements in the final samples taken, respectively. Figure 12 shows the measured Ag, Co, Ga, Mo, $\mathrm{Sb}, \mathrm{Sr}, \mathrm{V}$, and $\mathrm{W}$ concentrations. In the case of reaction at $100^{\circ} \mathrm{C}, \mathrm{Co}, \mathrm{Sr}$, and $\mathrm{Ga}$ were mobilised at concentrations of $160 \mathrm{ppb}, 150 \mathrm{ppb}$, and $10 \mathrm{ppb}$, respectively. Reaction at $200^{\circ} \mathrm{C}$ resulted in the mobilisation of $7100 \mathrm{ppb} \mathrm{Sb}, 980 \mathrm{ppb}$ Co, 220 ppb Sr, 180 ppb Mo, 8 ppb Ga, and 8 ppb W.

4.2. Flow-through Measurements. Experiments using the flow-through reactor described in the methods section were conducted using deionised (DI) water and $0.1 \mathrm{M}$ acetic acid on samples HTL315, HTL139, HTL321, HTL322, HTL324, and HTLMix at 200 and $250^{\circ} \mathrm{C}$ temperature under $250^{\circ}$ bar pressure. A summary of the actual physical properties during the flow-through tests is represented by Table 6. Leachate samples from each reaction were analysed using ICP-MS. Data about the composition of samples from the flowthrough reaction, on which the following figures are based, can be found in Tables 7 and 8 .

4.2.1. Leaching Tests Using Deionised Water. Flow-through leaching experiments were carried out using deionised water on samples HTL321, HTL322, and HTL324 at $200^{\circ} \mathrm{C}$. The concentration of "common" elements leached can be seen in Figure 13, and the concentration of "at risk" elements mobilised from solid samples is presented in Figure 14.

The total concentration of the selected "common" elements in HTL321 is approximately $1000 \mathrm{ppm}$ (of which $380 \mathrm{ppm}$ is Ca and $380 \mathrm{ppm}$ is S); for HTL322, the total leached is $90 \mathrm{ppm}$ (of which $40 \mathrm{ppm}$ is $\mathrm{Ca}$ and $27 \mathrm{ppm}$ is $\mathrm{S}$ ); for HTL324, the total is $940 \mathrm{ppm}$ (of which $480 \mathrm{ppm}$ is $\mathrm{Ca}$ and $360 \mathrm{ppm}$ is S). Reaction with deionised water resulted in a total concentration of $400 \mathrm{ppb}$ of the selected "at risk" elements in the case of HTL321, $700 \mathrm{ppb}$ in the case of HTL322, and $520 \mathrm{ppb}$ in the case of HTL324. The highest concentration element among the "at risk" elements was $\mathrm{Sr}$, representing $94 \%, 94 \%$, and $76 \%$ of the total amount of "at 


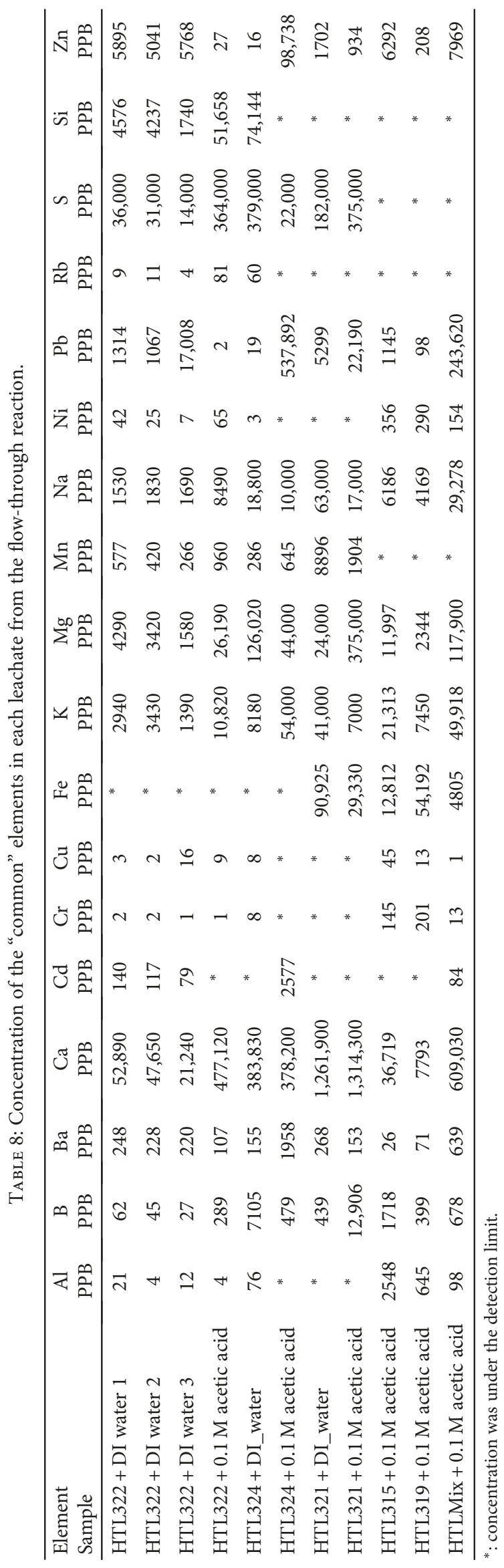



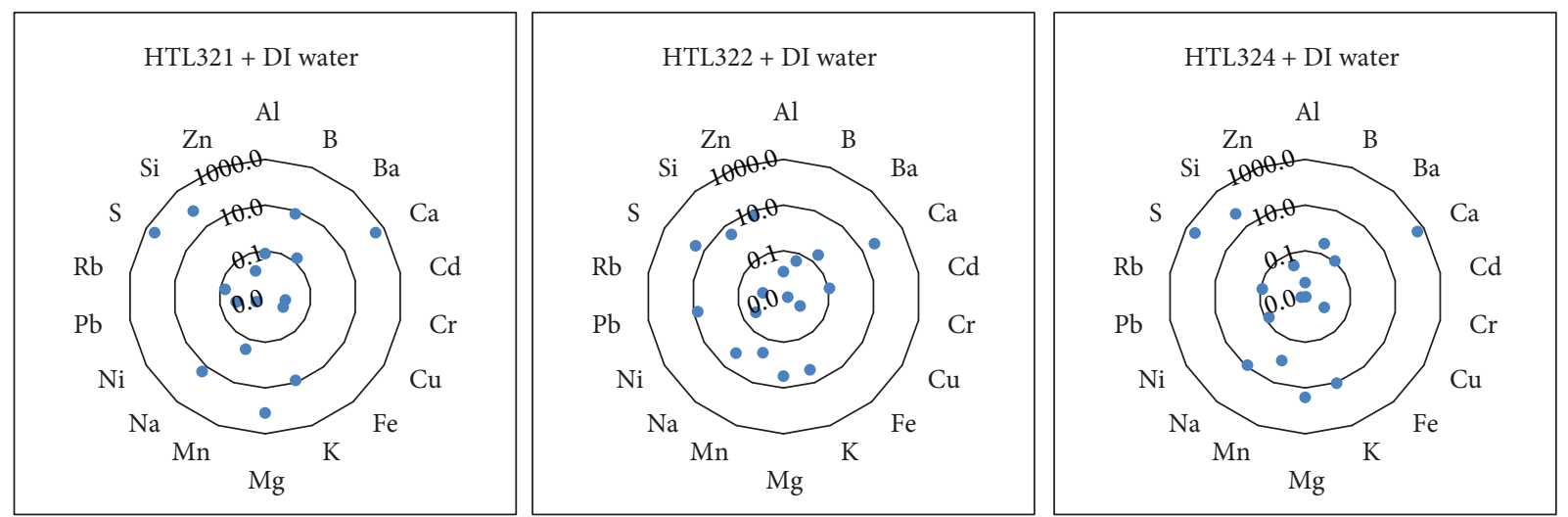

FIGURE 13: Elemental composition (in ppm) of each leachate from samples reacted with deionised water at $200^{\circ} \mathrm{C}$ temperature under 250 bar pressure in the flow-through reactor after 52 minutes, 48 minutes, and 25 minutes, respectively (absence of data points reflects concentrations below the limits of detection).
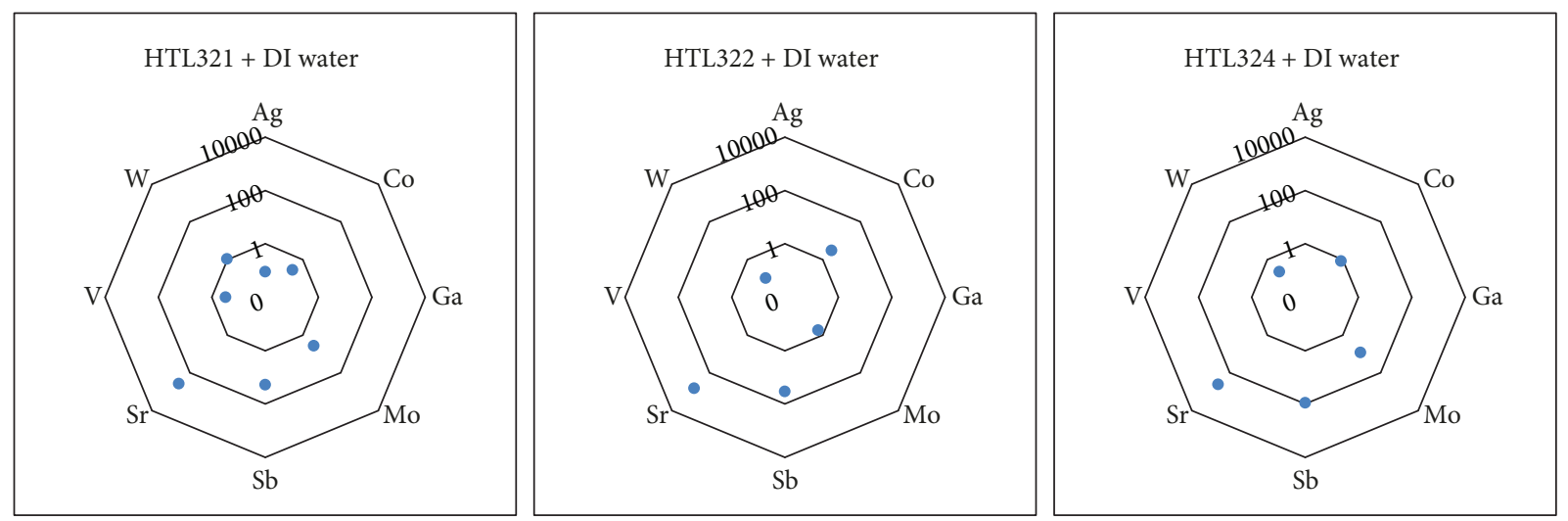

FIgURE 14: The amount of "at risk" elements in leachate from samples reacted with deionised water at $200^{\circ} \mathrm{C}$ temperature under 250 bar pressure in ppb after 52 minutes, 48 minutes, and 25 minutes, respectively (absence of data points reflects concentrations below the limits of detection).

risk" elements in the leachates, respectively. Sb and $\mathrm{W}$ were also detected amongst other potentially useful elements.

4.2.2. Leaching Tests Using Acetic Acid as Solvent. Flowthrough leaching experiments were also carried out using $0.1 \mathrm{M}$ acetic acid. Total dissolved solids (TDS) concentrations in the leachates from these experiments were too high to use the ICP-MS analysis previously employed; therefore, an instrument meant for midgrade concentrations, ICP-OES, was used. This method had a higher detection limits for some crucial elements; therefore, it was useful only in the determination of the concentrations of the most abundant elements. The concentrations of elements in the leachate as a result of the reaction can be seen in Figure 15.

The total concentrations of "common" elements leached, shown in Figure 15, correspond to approximately $1060 \mathrm{ppm}$ in the case of HTLMix, $100 \mathrm{ppm}$ in the case of HTL315, $80 \mathrm{ppm}$ in the case of HTL319, $2150 \mathrm{ppm}$ in the case of HTL321, $1150 \mathrm{ppm}$ in the case of HTL322, and $1680 \mathrm{ppm}$ in the case of HTL324. Generally, the most abundant element in the leachates was $\mathrm{Ca}$, constituting $57 \%, 36 \%, 10 \%, 61 \%$, $33 \%$, and $75 \%$ of the total "common" elements in leachates from experiments using HTLMix, HTL315, HTL319, HTL321, HTL322, and HTL324, respectively. In the case of HTLMix and HTL322, enhanced Pb release was experienced with concentrations of $240 \mathrm{ppm}$ and $540 \mathrm{ppm}$ in the leachates from these samples, respectively.

Reaction with $0.1 \mathrm{M}$ acetic acid at $250^{\circ} \mathrm{C}$ temperature under 250 bar pressure resulted in total concentrations of the selected "at risk" elements of $1030 \mathrm{ppb}, 230 \mathrm{ppb}$, $1100 \mathrm{ppb}, 1100 \mathrm{ppb}, 2840 \mathrm{ppb}$, and $1530 \mathrm{ppb}$ for leachates from experiments using HTLMix, HTL315, HTL 319, HTL321, HTL322, and HTL324, respectively. Figure 16 shows the concentrations of $\mathrm{Ag}, \mathrm{Co}, \mathrm{Ga}, \mathrm{Mo}, \mathrm{Sb}, \mathrm{Sr}, \mathrm{V}$, and $\mathrm{W}$ in these samples.

In HTLMix, Ag was detected at a concentration of $20 \mathrm{ppb}$. In HTL315, $10 \mathrm{ppb}$ of $\mathrm{V}$ was detected together with $\mathrm{Sr}$ and $\mathrm{Co}$. The widest range of elements was mobilised from HTL319 with leachate concentrations of $440 \mathrm{ppb}$ Sb, $95 \mathrm{ppb}$ $\mathrm{Sr}, 90 \mathrm{ppb} \mathrm{Ag}$, and $9 \mathrm{ppb} \mathrm{Co}$; $\mathrm{W}$ was also detected in a notable amount at a concentration of $470 \mathrm{ppb}$. In the cases of HTL321, HTL322, and HTL324, only Sr was detected in one of the largest concentrations in the leachates at concentrations of $1090 \mathrm{ppb}, 2840 \mathrm{ppb}$, and $1530 \mathrm{ppb}$, respectively. 

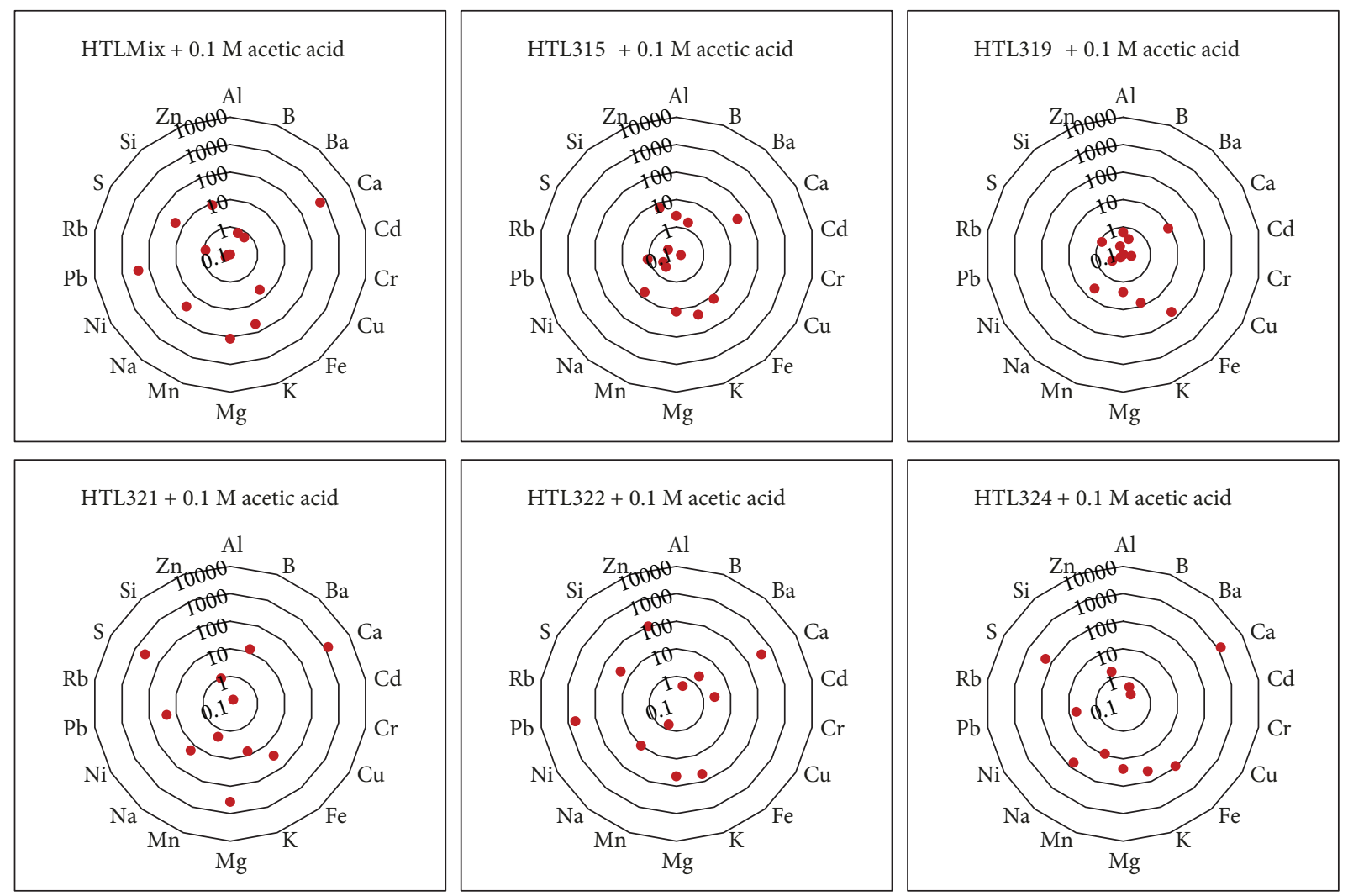

FIGURE 15: Elemental composition of each leachate reacted with $0.1 \mathrm{M}$ acetic acid at $250^{\circ} \mathrm{C}$ temperature under 250 bar pressure in the flowthrough reactor after $36,37,42,27,38$, and 48 minutes, respectively (absence of data points reflects concentrations below the limits of detection).

\section{Discussion}

5.1. Comparison of Different Fluids. The tests in this study were designed largely to test the efficacy of different leaching agents. While aggressive fluids, such as mineral acids, clearly have more potential to dissolve rock and associated mineralisation, this is not the only consideration in such a system. Also, of primary concern are the environmental impact of the fluids used and the impact on the reservoir and infrastructure. While a mineral acid may leach larger concentrations of desirable elements, it is also likely to attack bulk rock, leaching less desirable elements. The latter may require consideration when it comes to reinjection or disposal or may cause problems of precipitation in the system (as commonly occurs for silica). Likewise, such fluids are likely to attack borehole and surface infrastructure materials and have a more environmental impact. More benign fluids, such as fresh water, mild acids, or organic leachants, are more likely to be publicly and environmentally acceptable but have the obvious trade-off of weaker leaching effects and potential instability at elevated temperatures (particularly in the case of organic leachants). Some investigation of the relative performance of potential leachants is therefore required and a comparison between our chosen leachants is provided below.

For each fluid studied (deionised water, $0.1 \mathrm{M}$ acetic acid, and with $0.13 \mathrm{M}$ mineral acid), one experiment was chosen from the batch tests to compare the dissolution properties of each fluid. Experimental runs which were conducted under very similar conditions were selected, and results from these are shown in Figure 17 for "common" elements and in Figure 18 for "at risk" elements. The figures include data from HTLMix reacted with deionised water at $200^{\circ} \mathrm{C}$ under 200 bar pressure for 670 hours with $0.1 \mathrm{M}$ acetic acid at $150^{\circ} \mathrm{C}$ under 200 bar pressure for 1000 hours and with $0.13 \mathrm{M}$ mineral acid at $200^{\circ} \mathrm{C}$ under 200 bar pressure for 530 hours.

The sum of mobilised "common" elements is approximately $80 \mathrm{ppm}, 300 \mathrm{ppm}$, and $213,000 \mathrm{ppm}$ in the case of deionised water, $0.1 \mathrm{M}$ acetic acid, and $0.13 \mathrm{M}$ mineral acid, respectively. The huge increase in total dissolved elements is largely due to the previously mentioned large amount of Si mobilised (approximately $211,000 \mathrm{ppm}$ ) in the case of the mineral acid experiment. This considerable attack on the silicates (largely quartz) present in the system by the more acidic fluids and such extremely high Si concentration indicates that the solution was highly effective at dissolving the matrix minerals. Such dissolution, leading to a reduction in solids volume and the associated increase in porosity, could expose more surfaces of metal-bearing minerals and also increase permeability and enhance fluid flow through the system. However, a higher dissolved load could also cause more precipitation on cooling. This highlights the duality of such fluids, enhancing reservoirs through increased 

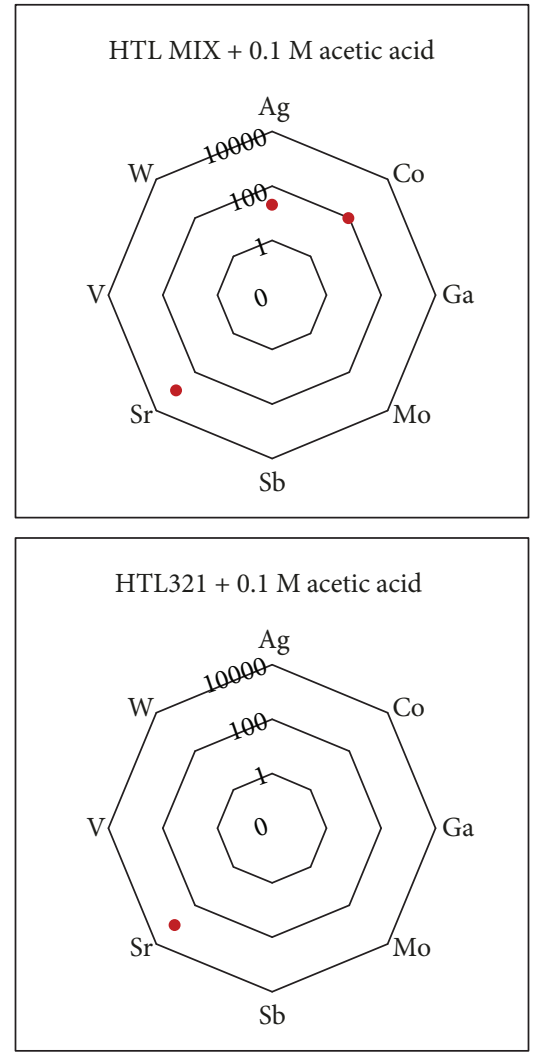
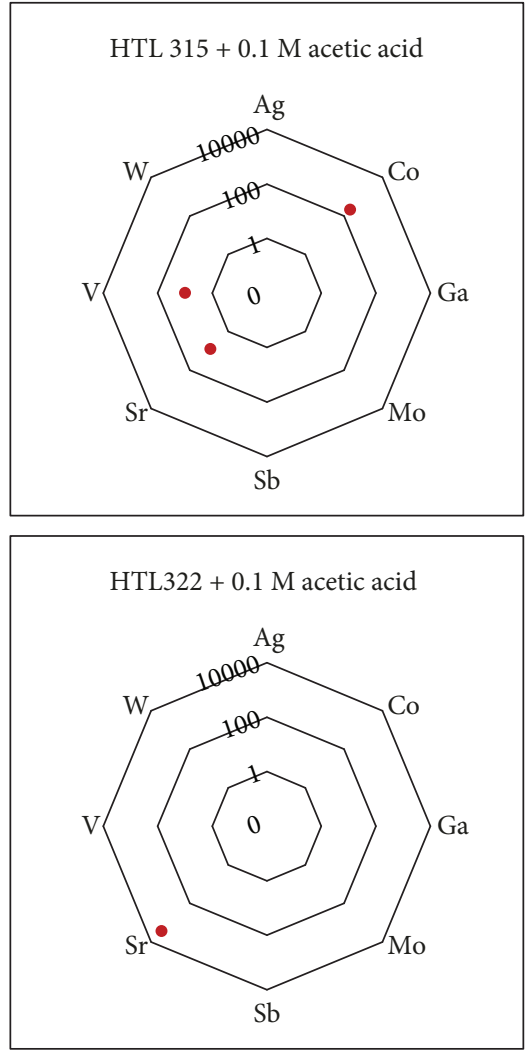
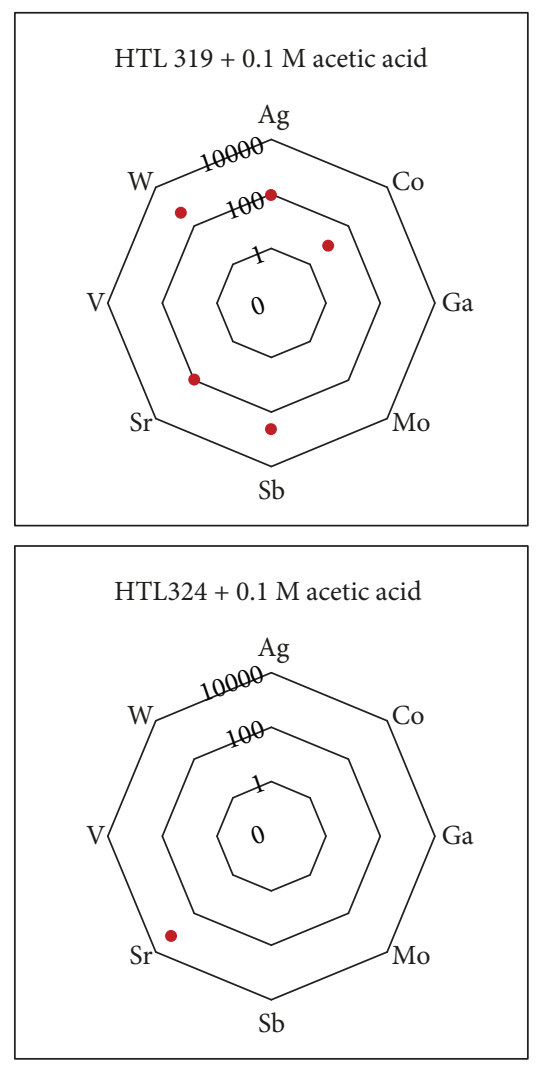

FIGURE 16: The amount of "at risk" elements in leachate samples reacted with $0.1 \mathrm{M}$ acetic acid at $250^{\circ} \mathrm{C}$ temperature under 250 bar pressure in ppb after 36, 37, 42, 27, 38, and 48 minutes, respectively (absence of data points reflects concentrations below the limits of detection).

permeability but potentially also leading to issues with precipitation in surface infrastructure.

Total concentrations of "at risk elements" are approximately $50 \mathrm{ppb}$ in the case of reaction with deionised water, $830 \mathrm{ppb}$ in the case of reaction with acetic acid, and $8500 \mathrm{ppb}$ when mineral acid was used. There is a strong relation between acidity and the total amount of mobilised elements. In our study, during batch experiments at higher temperatures, mineral acid was the best solvent, resulting in relatively high metal mobilisation and high concentration of $\mathrm{Al}$ and $\mathrm{Si}$, which in practice would mean a higher risk for scaling. Leaching with acetic acid resulted in moderate metal concentration and significantly lower $\mathrm{Al}$ and $\mathrm{Si}$ concentrations, suggesting this as a viable leaching option and a good compromise between useable metal release and scaling risk. Also, it could be more challenging to use mineral acids as leaching solvent in geothermal systems due to difficulties around transportation, handling, storage, and environmental issues. In terms of mobilised "at risk" elements, acetic acid was more effective than deionised water but less so than mineral acid (both in terms of dissolved concentrations and the spread of elements leached in detectable concentrations). Even though it is difficult to quantify the environmental impact, the additional leaching potential of mineral acid is unlikely to make use of such an aggressive fluid, even when used at relatively dilute concentrations as here, acceptable. The results indicate, however, that even a relatively mild leachant, such as acetic acid, with which the public is familiar as an everyday substance, can substantially increase leaching potential. In this case, a switch from deionised water to acetic acid generates a nearly 20-fold increase in the dissolved load of the selected "at risk" elements. Naturally, acetic acid may not be suitable for use under all circumstances; organic acids have a tendency to break down at elevated temperatures for example (though the natural breakdown of an injectant may be seen as desirable in the long term), but these results highlight the potential of using such, relatively simple, fluids to enhance leaching in an EGS system.

5.1.1. Batch Experiments. A time series of elemental concentrations from HTLMix reacted with $0.13 \mathrm{M}$ mineral acid at $100^{\circ} \mathrm{C}$ temperature under 200 bar pressure in a batch reactor is shown in Figure 19. Samples shown in the figure were collected after 70 hours, 290 hours, and 770 hours of reaction.

The total concentration of the selected elements in the first sample was approximately $4190 \mathrm{ppm}, 4220 \mathrm{ppm}$ in the second sample, and $4480 \mathrm{ppm}$ in the third sample. The trend shows a slight, but steady, increase in leachate concentrations over time for most elements. The notable exception to this trend is iron, which after an initial increase can be seen to decrease over the course of the experiment, indicating some reprecipitation or scavenging of this element. Leaching efficiency is largest at the beginning of the experiment and decreases over time in the case of every element. 


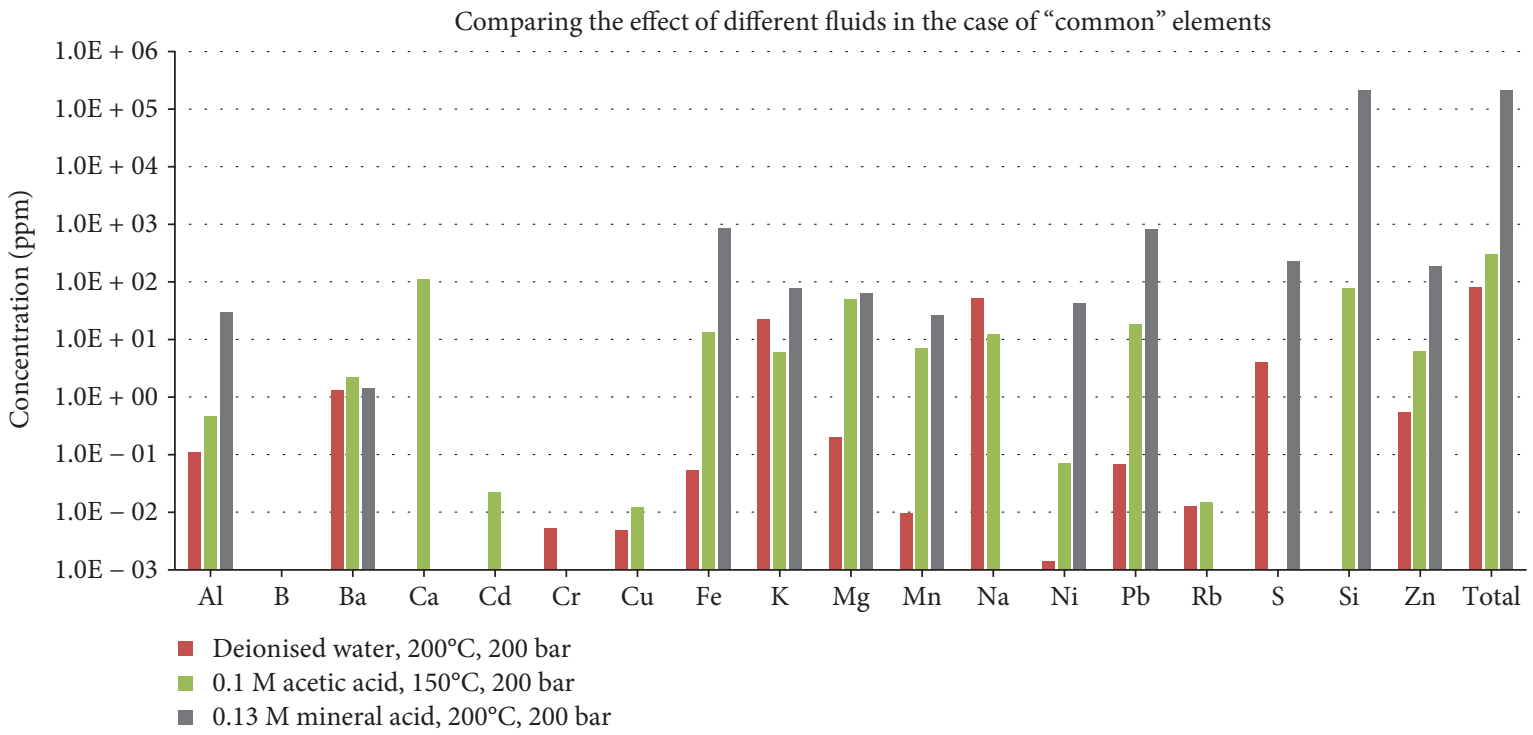

Figure 17: Comparison of the effectiveness of different fluids for "common" elements with concentrations in ppm.

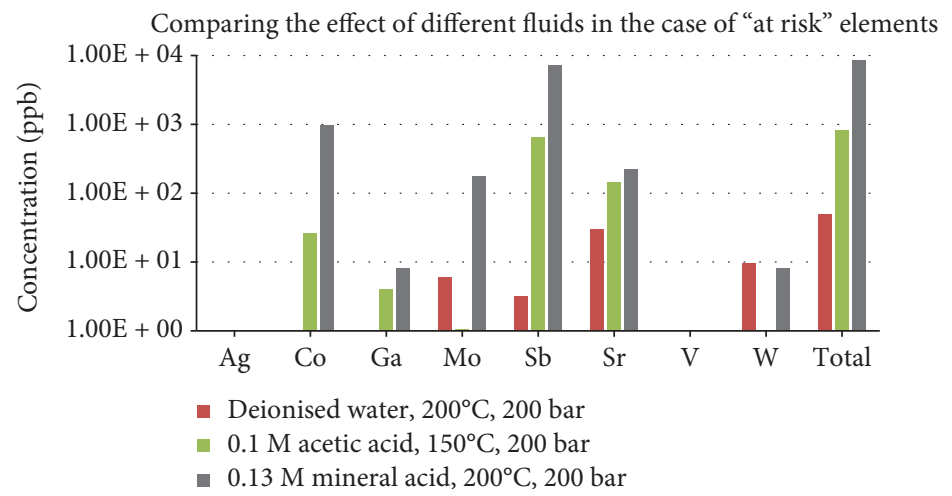

Figure 18: Comparison of the effectiveness of different fluids for "at risk" elements with concentrations in ppb.

Exceptionally high concentrations of $\mathrm{Pb}$ were detected at concentrations of approximately $3530 \mathrm{ppm}, 3520 \mathrm{ppm}$, and $3680 \mathrm{ppm}$ after $70 \mathrm{~h}, 290 \mathrm{~h}$, and $770 \mathrm{~h}$ reaction, respectively. Leaching was most rapid in the first 70 hours, mobilising $3530 \mathrm{ppm} \mathrm{Pb}$, and then decreased radically, only increasing $\mathrm{Pb}$ concentrations by $150 \mathrm{ppm}$ over the remaining 700 hours of the experiment, as the system approached equilibrium.

Available surface area for a chemical reaction (and heat exchange) is crucial for raw material mobilisation, as mineralised rock formations dissolve quickly, suggesting that increasing available surface through stimulation might be more effective in increasing dissolved load rather than increasing the path length or residence time in the reservoir [19]. On a reservoir scale, this would mean that the targeted metal-rich ore formation is depletable and extraction would be most efficient early on in an extraction project with returns likely to decrease relatively rapidly over time [20]. The lifespan of such a metal extraction facility would be highly dependent on the size and grade of the geological formation but would likely be shorter than the plant life of a geothermal energy-producing facility without managing the reservoir in such a way that injected fluid could contact fresh surfaces regularly, i.e., through redirection of groundwater flow or through mechanical stimulation of the reservoir, creating fresh surfaces.

5.1.2. Flow-through Measurements. In addition to fresh surface area, another limiting factor in potential metal extraction will be the volume of "fresh" fluid that can be passed through the reservoir. In the batch experiments above, reactions can be seen slowing dramatically within a few 10 s of hours as equilibrium is approached. Therefore, comparison with flow-through experiments can be instructive. A time series of elemental concentrations from one of the flow-through experiments is shown in Figure 20. Samples shown in the figure represent concentrations from reactions in the first 36 minutes, 37-84 minutes, and 85-119 minutes.

The total concentration of the shown elements in the first sample was approximately $110 \mathrm{ppm}, 98 \mathrm{ppm}$ in the second sample, and $65 \mathrm{ppm}$ in the third sample. This trend in leachate concentrations is not element specific; the concentrations 


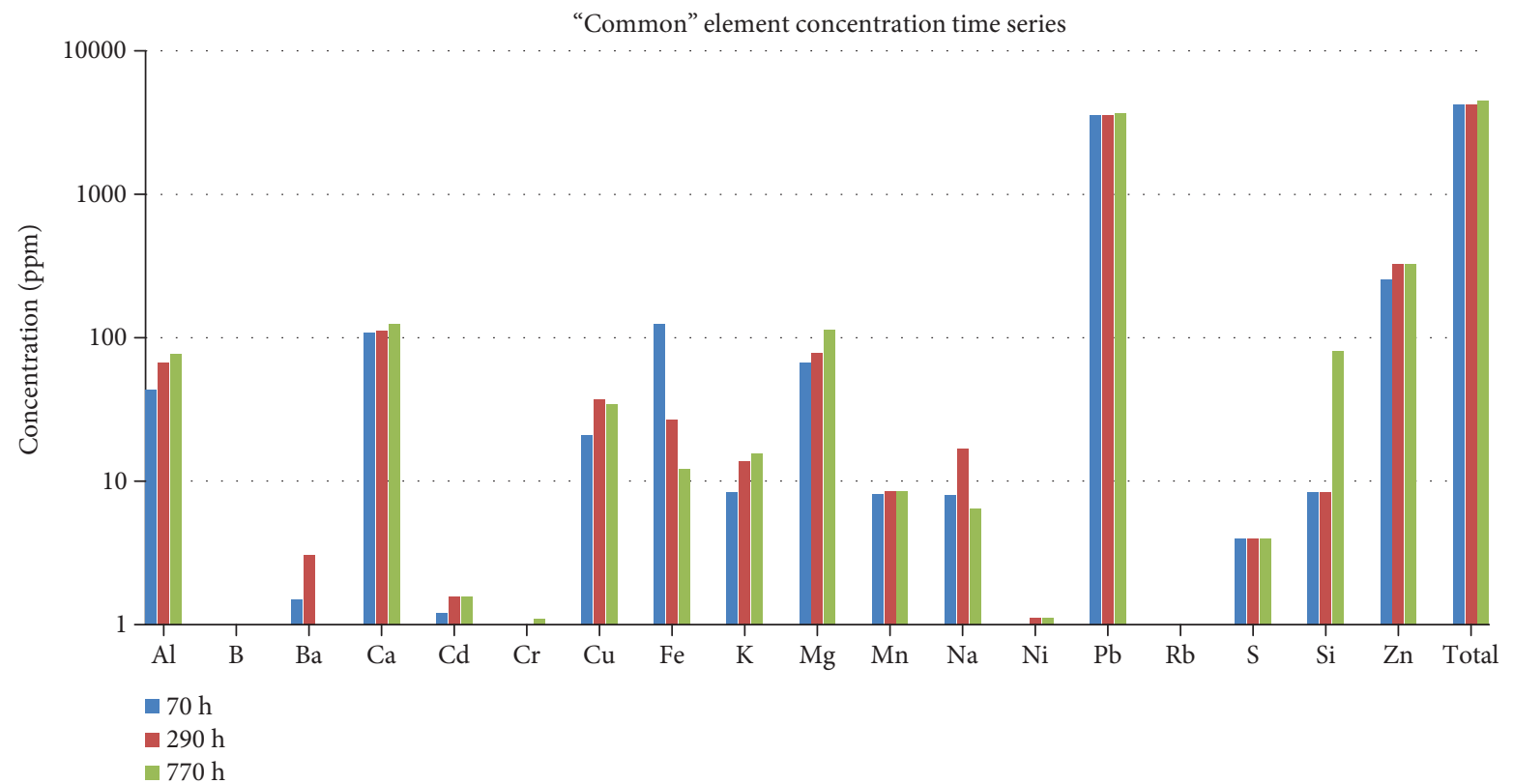

Figure 19: The kinetics of elemental composition over time in leachates from HTLMix sample reacted with $0.13 \mathrm{M}$ mineral acid at $100^{\circ} \mathrm{C}$ temperature under 200 bar pressure in the batch reactor after 70, 290 and 770 hours, respectively.

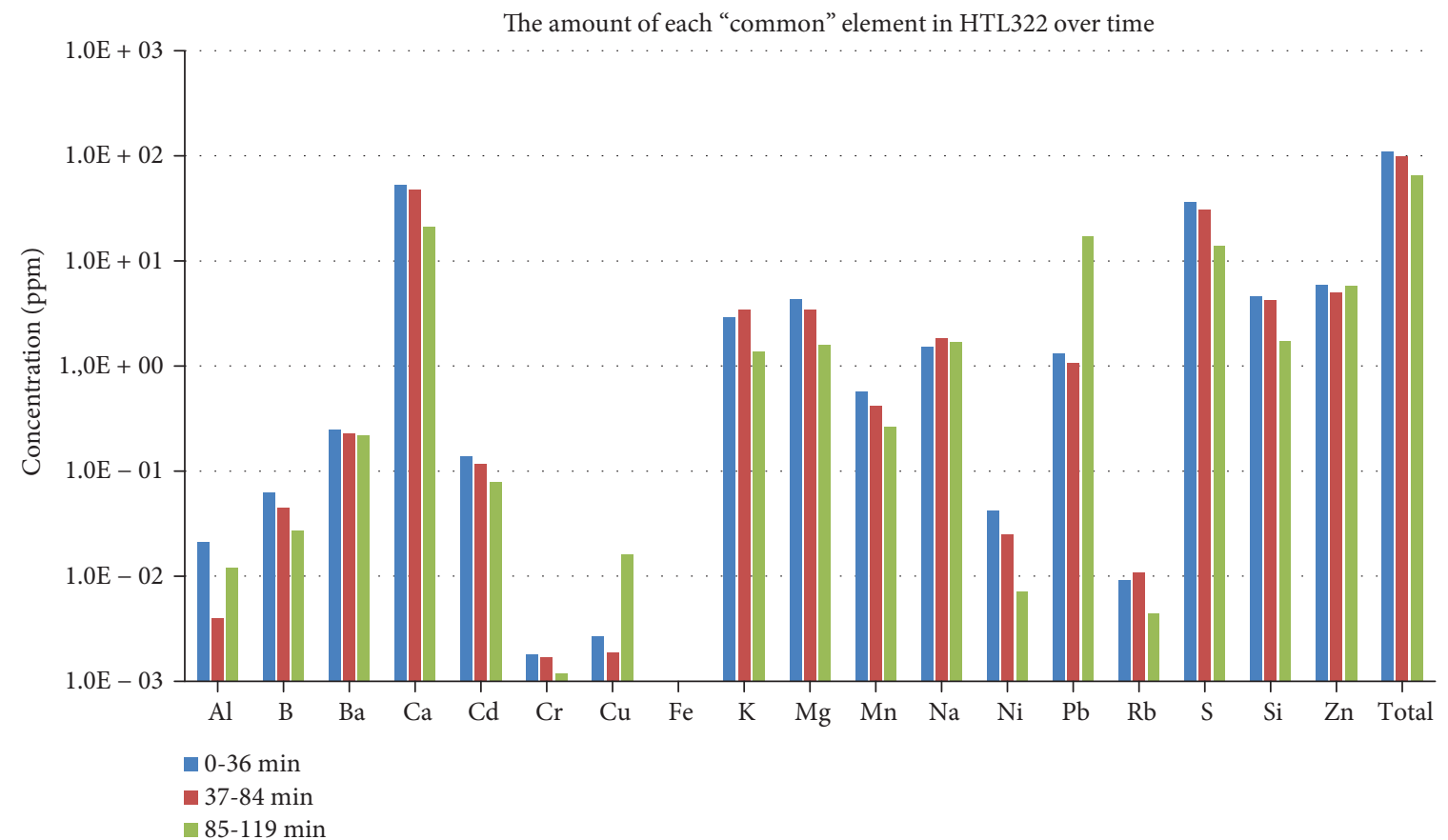

Figure 20: The kinetics of elemental composition over time in leachates from HTL322 sample reacted with deionised water at $200^{\circ} \mathrm{C}$ temperature under 250 bar pressure in the flow-through reactor after 36, 84, and 119 minutes, respectively.

of Ca (53 ppm, $47 \mathrm{ppm}$, and $21 \mathrm{ppm}), \mathrm{Mg}(4 \mathrm{ppm}, 3 \mathrm{ppm}$, and $1.5 \mathrm{ppm}), \mathrm{Mn}$ (580 ppb, $420 \mathrm{ppb}$, and $270 \mathrm{ppb}), \mathrm{S}(35 \mathrm{ppm}$, $30 \mathrm{ppm}$, and $15 \mathrm{ppm})$, and $\mathrm{Si}(5 \mathrm{ppm}, 4 \mathrm{ppm}$, and $1.5 \mathrm{ppm})$ amongst others show this trend, too. Even though the concentration of total dissolved "common" elements increased over time, the amount of increase decreased.

The tendency shown by these graphs indicates a rapid leaching reaction (for the first sample the contact time was
36 minutes). Dissolution of solid material occurs most rapidly during earlier times and then continues at lower dissolution rates. This is a key factor to consider when designing the circulation rate of an EGS system, which controls the residence time of the fluid in the reservoir. When combining metal leaching with the harnessing of geothermal energy, the rock dissolution processes for metal mobilisation would have longer contact times than those demonstrated here; 


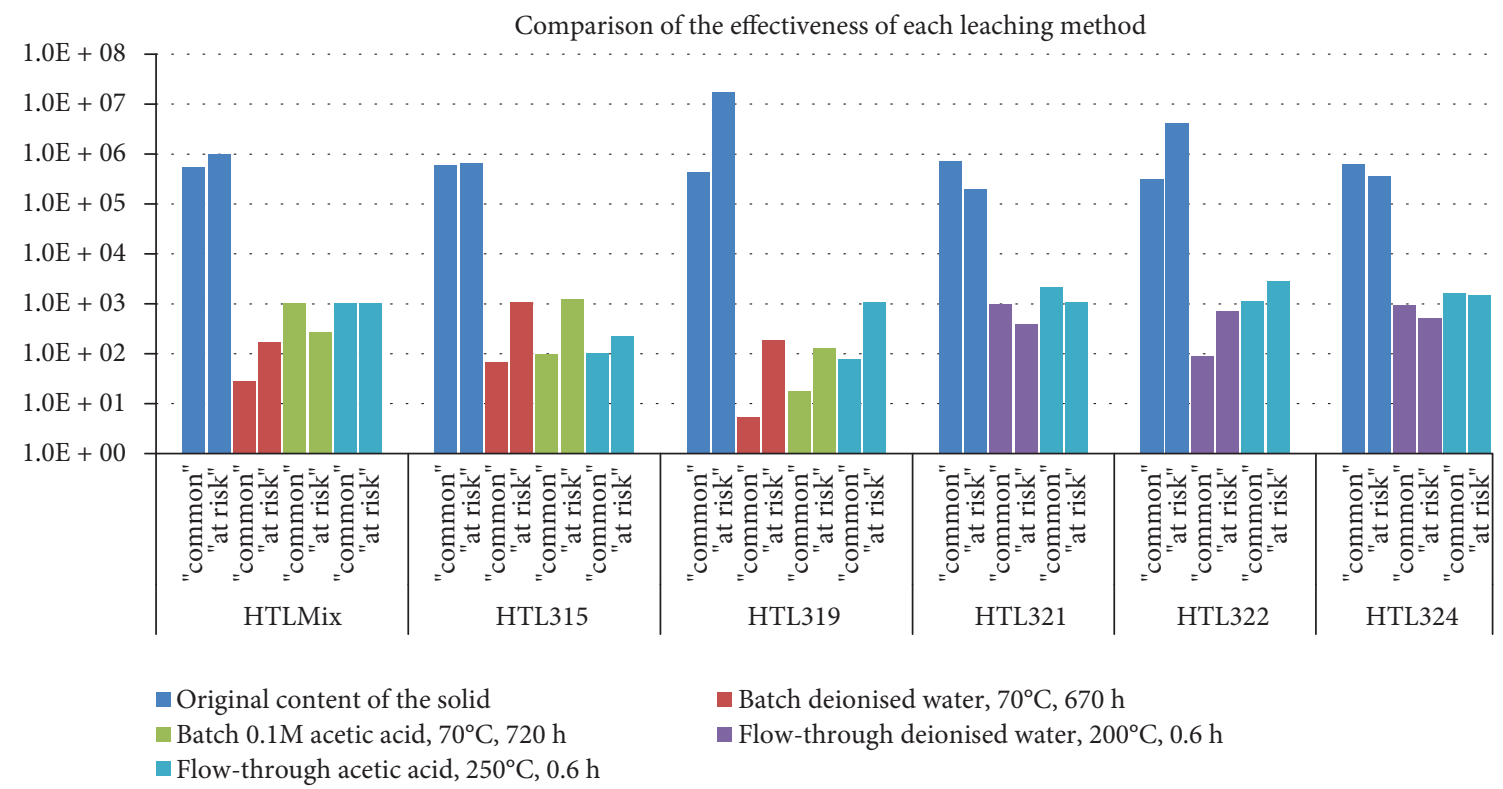

FIGURE 21: Comparison of rock sample composition to results from the batch and flow-through leaching experiments with deionised water and acetic acid as solvent. Important to note that the axis is logarithmic and the concentrations of "common" elements are in ppm and the concentrations of "at risk" elements are in ppb.

TABLE 9: Concentration of the "at risk" elements in each solid rock sample.

\begin{tabular}{|c|c|c|c|c|c|c|c|c|c|}
\hline $\begin{array}{l}\text { Element } \\
\text { Sample }\end{array}$ & $\begin{array}{c}\mathrm{Ag} \\
\mathrm{PPB}\end{array}$ & $\begin{array}{l}\text { Co } \\
\text { PPB }\end{array}$ & $\begin{array}{l}\mathrm{Ga} \\
\mathrm{PPB}\end{array}$ & $\begin{array}{l}\text { Mo } \\
\text { PPB }\end{array}$ & $\begin{array}{c}\mathrm{Sb} \\
\mathrm{PPB}\end{array}$ & $\begin{array}{c}\mathrm{Sr} \\
\mathrm{PPB}\end{array}$ & $\begin{array}{c}\mathrm{V} \\
\mathrm{PPB}\end{array}$ & $\begin{array}{c}W \\
\text { PPB }\end{array}$ & $\begin{array}{c}\text { Total 'at risk' } \\
\text { PPB }\end{array}$ \\
\hline HTLMix & 45258.83 & 4169.87 & 4272.66 & 223.06 & 861478.98 & 16679.67 & 20292.37 & 42936.29 & 995311.73 \\
\hline HTL315 & 11973.44 & 249443.41 & 9746.84 & 780.91 & 145129.71 & 15440.17 & 7738.55 & 216446.11 & 656699.15 \\
\hline HTL319 & 639.66 & 430.16 & 1195.83 & 1533.93 & 5513.29 & 9968.94 & 718.91 & 17678896.30 & 17698897.02 \\
\hline HTL321 & 424.80 & 78783.79 & 1392.45 & 700.33 & 58165.19 & 15421.11 & 22437.25 & 25124.42 & 202449.34 \\
\hline HTL322 & 534398.93 & 4028.59 & 1282.41 & 2386.12 & 2497731.37 & 1156992.59 & 2913.91 & 9290.47 & 4209024.39 \\
\hline HTL324 & 3098.11 & 48344.41 & 17976.82 & 20344.31 & 694.81 & 5236.13 & 258590.19 & 6466.08 & 360750.86 \\
\hline
\end{tabular}

therefore, results from this study could be considered as minimum thresholds.

In both experimental setups, the solid sample used was powdered rather than a whole rock. This form of material might have several high energy sites caused by the sample preparation, leading to relatively high dissolution rates over the course of the experiments. This might also be the case in a geothermal reservoir which has been stimulated. New fresh surfaces with which the fluid may react, leading to high initial loads, which will tail off with time. If no stimulation is being carried out, dissolution may be lower, but steady. The fresh surface area in a reservoir will be relatively low, but the contact time will be much longer than that shown here. Contact time for fluid-rock interactions in case of batch reactions was average 30 days maximum, while flow-through tests had less than 1 hour contact time (but much more solid material and hence available surface area). In an operating EGS plant in Europe, the average travel time of the fluid was 23 days, depending on the flow path $[21,22]$. It will be important to consider these effects when looking at the whole life-cycle of a project, possibly resulting in high recovery initially, tailing off later on, without continued stimulation or exposure of new surfaces.

5.1.3. Summary. While batch experiments are useful in rapidly elucidating relative leaching potentials of various fluids, the results they produce are often difficult to compare to "real" systems due to very high fluid-rock ratios and the fact that they represent a closed system with no input of fresh fluid. As part of this work, therefore, flow-through experiments were also carried out, allowing a direct comparison between the two system types. Figure 21 is a summary of the experiments conducted with deionised water and acetic acid. It displays the total concentrations of "common" and "at risk" elements from all initial solid samples and next to it in each leachate. Data about the composition of solid rock samples, on which the following figures are based, can be found in Tables 9 and 10 .

The data in Figure 21 has been broken down to Figure 22, which compares the total concentration of "common" elements in the final leachates, and Figure 23, which focuses on the more critical "at risk" elements. 


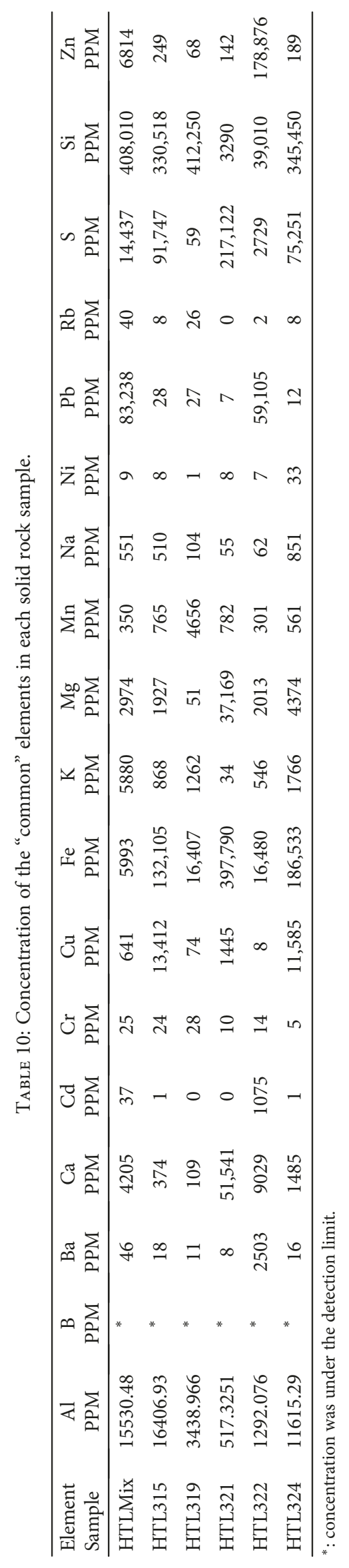




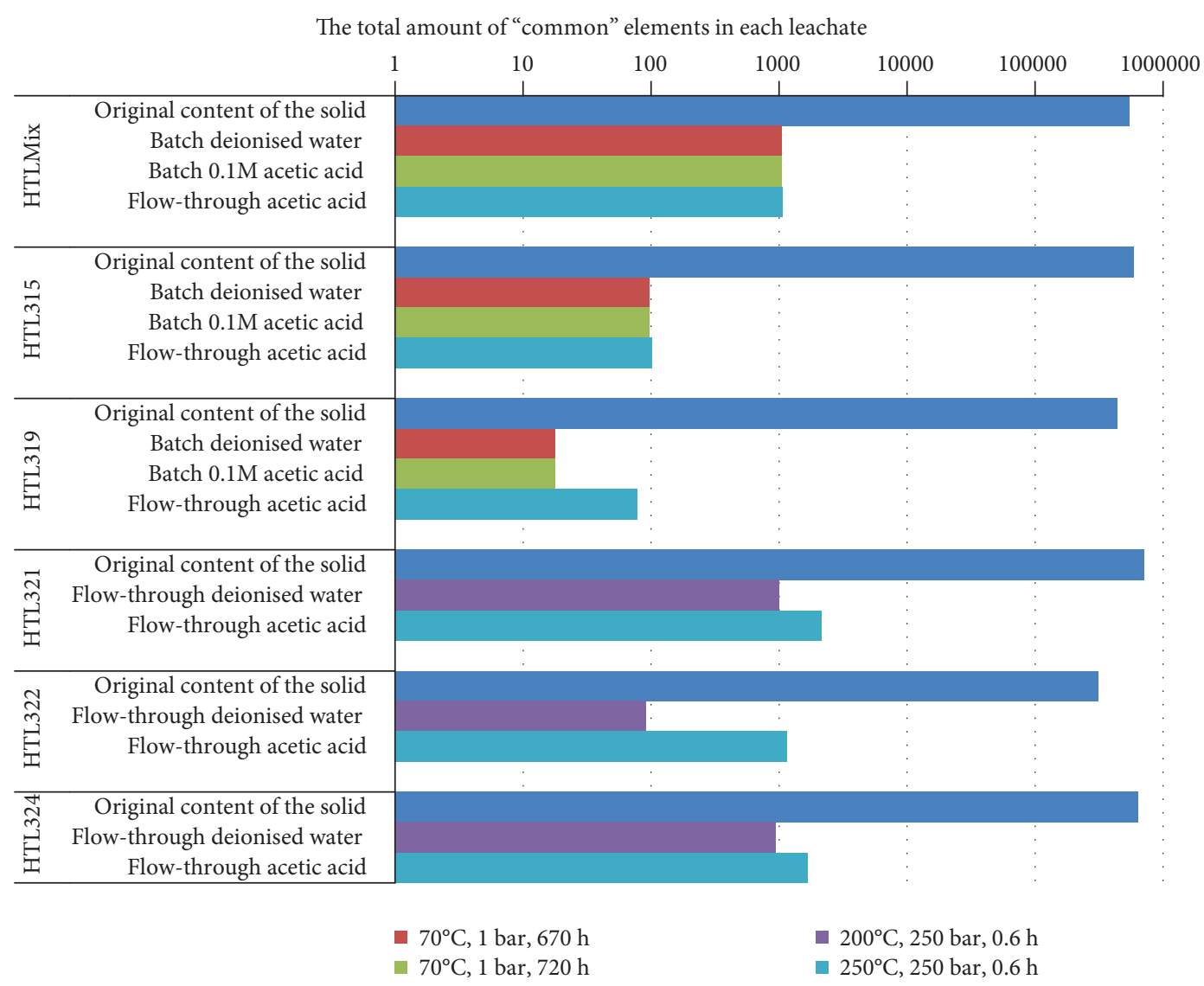

FIGURE 22: Summarising chart of detected "common" elements during each experiment with concentrations in ppm.

As shown in Figure 22, acetic acid has a much better potential to dissolve "common" elements relative to deionised water. The experiment carried out using HTL322 and different fluids is a good example for this; acetic acid (mobilising $0.368 \%$ of the original content) resulted in an almost 13 times increase in the concentration of "common" elements over deionised water (mobilising $0.029 \%$ of the original content). Based on these samples, however, flow-through reactions yielded in slightly higher total dissolved element concentrations than batch reactions, even over relatively short contact times. This in part was due to a considerably lower fluid to rock ratio used in the flow-through experiments, which also indicates that the availability of fresh surface area is an important factor in determining leaching rates. Given the rapidity of reaction in the flow-through experiments, these results indicate that even in a reservoir where fresh surface area is more limited than that used here, reasonably high dissolved loads should be achievable, especially given the much greater contact times between fluid and mineral in such systems. The spider plots of these reactions show similar patterns, in terms of leachate elemental compositions, in both experimental setups.

In some of the flow-through experiments (e.g., flowthrough reaction with $0.1 \mathrm{M}$ acetic acid and HTL321), elements are observed in the leachates at very elevated (>1000 ppm) concentrations. Generally, $\mathrm{Ca}, \mathrm{Fe}, \mathrm{Mg}$, and S were the most abundant elements in the leachates, all of which are associated with scale formation. During laboratory tests, no scaling in the equipment or in the tubing was observed. Figure 23 shows only the concentration elements which we have defined as "at risk".

The trend of mobilisation of "at risk" elements correlates to that of "common" elements. Acetic acid proved to be far more effective than deionised water in all cases. One of the most effective dissolution of "at risk" elements was in the case of HTL321 reacted with $0.1 \mathrm{M}$ acetic acid, where $0.54 \%$ of the original content could be mobilised. This is 1.5 times more effective than the best result at "common" elements. Sr, Co, $\mathrm{W}$, and Mo elements were leached at the highest concentrations, indicating the potential for further investigations due to the criticality of tungsten and cobalt.

\section{Conclusions}

Laboratory batch and flow-through leaching tests were run in the range of $70-250^{\circ} \mathrm{C}$ under $1-300$ bar pressure, conditions which include the properties of an average geothermal reservoir at $3 \mathrm{~km}$ depth. As a result of the reactions in the laboratory, reasonable concentrations of a wide range of elements could be mobilised. Detected elements were grouped as "common" and "at risk" elements. Selected "common" elements have less economic importance and higher occurrence (in both the solid samples used and the produced leachates), 


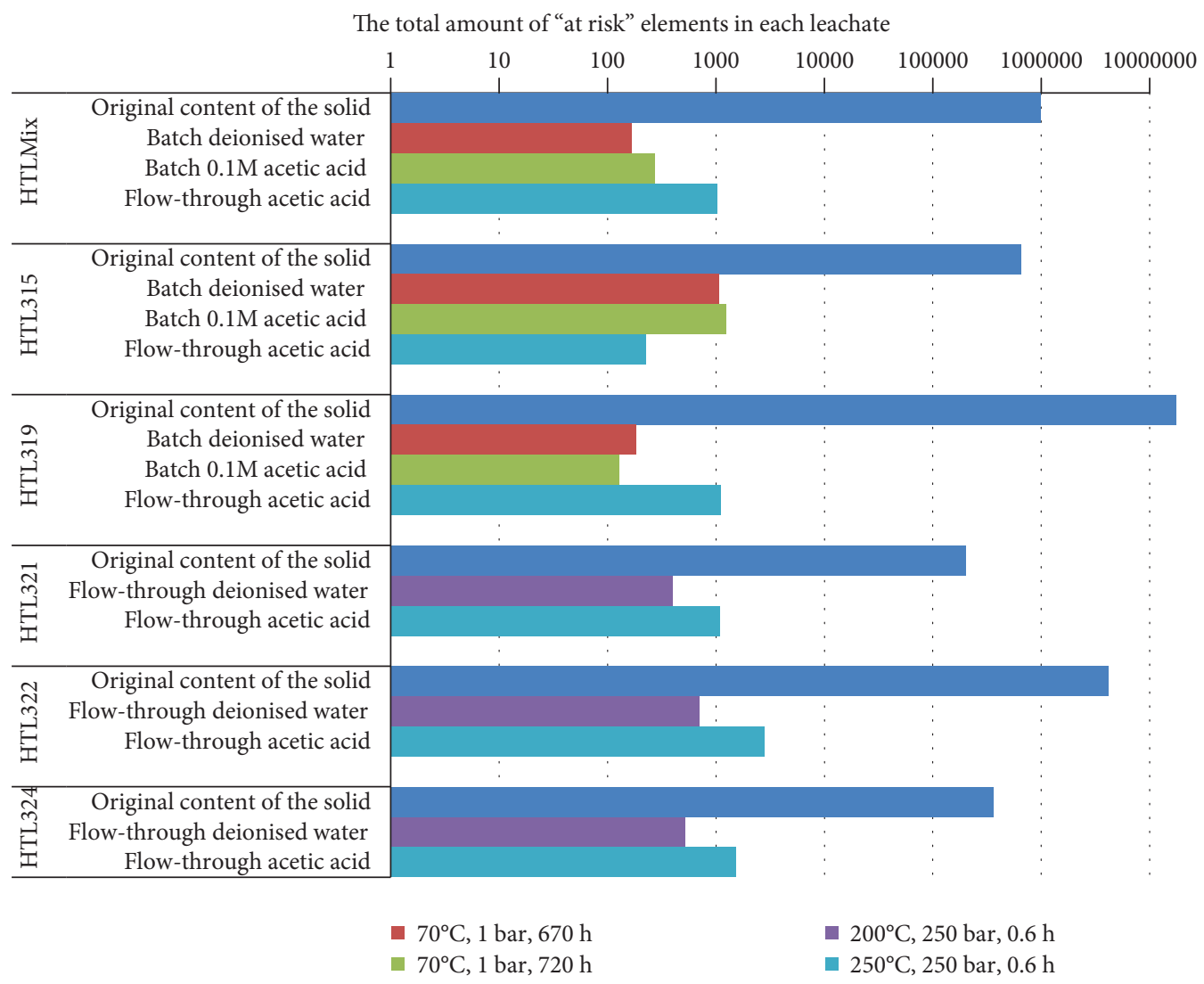

FIGURE 23: Summarising chart of detected "at risk" elements during each experiment with concentrations in ppb.

while our selected "at risk" elements have higher economic value, and lower supply security.

One of the highest concentrations of "common" elements occurred in the case of lead, which mobilised at concentrations of up to $870 \mathrm{ppm}$ with acetic acid during the batch reaction and up to $540 \mathrm{ppm}$ in the flow-through reactor. Notable concentrations of $\mathrm{Zn}$ are also present in leachates, which corroborates the enhanced dissolution progress. In laboratory tests, significant $\mathrm{Al}$ and $\mathrm{Si}$ were also found. Elevated concentrations of these elements indicate considerable dissolution of matrix silicates present in the samples. This could be desirable in terms of increasing reservoir permeability and opening flow paths, but if concentrations become too high, there is an increased risk of precipitation, which could clog fractures and inhibit fluid flow in a geothermal reservoir, and risk fouling boreholes or surface infrastructure. In a technologically optimised geothermal reservoir, where extraction would target metals but not necessarily in their pure forms (i.e., could include extraction of metals complexed with some of the scale-forming elements), therefore as they are removed from the fluid in a technological material extraction step, the risk of clogging would decrease in the reservoir and in the well. In this way, metal extraction would reduce natural scaling and therefore increase efficiency.

The highest concentration of a single element detected from the "at risk" group was 1070 ppb Co concentration in batch reactors with acetic acid and $2840 \mathrm{ppb} \mathrm{Sr}$ concentration in a flow-through setup with acetic acid. During all leaching tests, $\mathrm{Sr}, \mathrm{Co}, \mathrm{W}$, and Mo were detected with the largest abundance, which is a good motivation towards further experiments as tungsten and cobalt have the highest economic risk rating for the EU, respectively.

In leaching reactions, even reasonably mild and environmentally acceptable fluids could be utilised to dissolve considerable amounts of silicate material as well as some elements of interest. Fast reaction rates given the right conditions (high temperature and pressure with good amount of available surface area) within the geothermal reservoir are promising in terms of potential to metal recovery. Future work and technological development is still needed to practically recover raw materials from geothermal fluids, as the desired concentrations for extraction tend to be higher than those achieved in this study. The results are intended to use for upscaling to reservoir scale and calculate likely dissolved loads achievable, given reaction rates and solubility of the various elements involved. In this study, the first steps were done to ensure the sustainability of the proposed technology, further investigations, advances in other technologies, and a full life cycle assessment study need to follow.

\section{Data Availability}

The ICP-MS and ICP-OES analysis data used to support the findings of this study are included within the article and within the appendices. All other previously reported (microscopic and XRD analyses) data used to support this study are 
available at http://www.chpm2030.eu. These prior studies (and datasets) are cited at relevant places within the text.

\section{Conflicts of Interest}

The authors declare that there is no conflict of interest regarding the publication of this paper.

\section{Acknowledgments}

The CHPM2030 project has received funding from the European Union's Horizon 2020 research and innovation programme under grant agreement No. 654100. The authors would like to express their gratitude to Richard Shaw, Jeremy Rushton, Alicja Lacinska, Dániel Füzéri, Simon Chenery, Andrew Marriot, Elliott Hamilton, Michael Watts, Ian Mountney, and Simon Kemp for providing support and analysis for the BGS experimental program.

\section{References}

[1] European Commission Directorate-General for Internal Market, Industry, Entrepreneurship and SMEs, Deloitte Sustainability; British Geological Survey, Bureau de Recherches Géologiques et Minières, and Netherlands Organisation for Applied Scientific Research 2017, "Study on the review of the list of critical raw materials: critical raw materials factsheets," 2017, https://publications.europa.eu/en/publicationdetail/-/publication/7345e3e8-98fc-11e7-b92d-01aa75ed71a1/ language-en.

[2] V. D. Dang and M. Steinberg, "Preliminary design and analysis of recovery of lithium from brine with the use of a selective extractant," Energy, vol. 3, no. 3, pp. 325-336, 1978.

[3] W. P. C. Duyvesteyn, "Recovery of base metals from geothermal brines," Geothermics, vol. 21, no. 5-6, pp. 773-799, 1992.

[4] S. E. Kesler, P. W. Gruber, P. A. Medina, G. A. Keoleian, M. P. Everson, and T. J. Wallington, "Global lithium resources: relative importance of pegmatite, brine and other deposits," Ore Geology Reviews, vol. 48, pp. 55-69, 2012.

[5] R. G. Bloomquist, "Economic benefits of mineral extraction from geothermal brines," Transactions - Geothermal Resources Council, vol. 30, pp. 579-582, 2006.

[6] G. Neupane and D. S. Wendt, "Assessment of mineral resources in geothermal brines in the US," in Proceedings of 42nd Workshop on Geothermal Reservoir Engineering Stanford University, Stanford, CA, USA, 2017.

[7] P. Bajcsi, T. Bozsó, R. Bozsó et al., "New geothermal wellcompletion and rework technology by laser," Central European Geology, vol. 58, no. 1-2, pp. 88-99, 2015.

[8] J. A. Marshall, A. Bonchis, E. Nebot, and S. Scheding, "Robotics in mining," in Springer Handbook of Robotics, B. Siciliano and O. Khatib, Eds., pp. 1549-1576, Springer, Cham, 2016.

[9] K. Breede, K. Dzebisashvili, X. Liu, and G. Falcone, "A systematic review of enhanced (or engineered) geothermal systems: past, present and future," Geothermal Energy, vol. 1, no. 1, p. 4, 2013.

[10] É. Hartai, N. Németh, and J. Földessy, CHPM2030 Deliverable D1.1: EGS-Relevant Review of Metallogenesis, Zenodo, 2016.
[11] S. Mullens, E. Moens, R. Kemps et al., Metal Content Mobilisation with Nanoparticles: CHPM2030 deliverable D2.3, CHPM2030, 2018.

[12] J. Szanyi, T. Medgyes, B. Kóbor et al., CHPM2030 Deliverable 5.1: Integrated Sustainability Assessment Framework, Zenodo, 2017.

[13] A. Kilpatrick, C. Rochelle, J. Rushton et al., Report on Metal Content Musing Mild Leaching, CHPM2030 Deliverable D2.2, Zenodo, 2017.

[14] N. Németh, J. Földessy, É. Hartai et al., EGS-Relevant Review of Orebody Structures: CHPM2030 Deliverable D1.3, Zenodo, 2016.

[15] K. Bateman, C. A. Rochelle, G. Purser, S. J. Kemp, and D. Wagner, "Geochemical interactions between $\mathrm{CO}_{2}$ and minerals within the Utsira caprock: a 5-year experimental study," Energy Procedia, vol. 37, pp. 5307-5314, 2013.

[16] C. A. Rochelle, A. E. Milodowski, K. Bateman, E. B. A. Moyce, and A. Kilpatrick, "A long-term experimental study of the reactivity of basement rock with highly alkaline cement waters: reactions over the first 15 months," Mineralogical Magazine, vol. 80, no. 6, pp. 1089-1113, 2016.

[17] Massachusetts Institute of Technology (MIT), The Future of Geothermal Energy: Impact of Enhanced Geothermal System (EGS) on the United States in the $21^{\text {st }}$ Century, Idaho National Laboratory, Idaho Falls, ID, USA, 2006, https://energy.mit. edu/wp-content/uploads/2006/11/MITEI-The-Future-of-Geo thermal-Energy.pdf.

[18] R. L. Snyder and D. L. Bish, "Quantitative analysis, Modern Powder Diffraction," in Reviews in Mineralogy, pp. 101-144, Mineralogical Society of America, Washington DC, USA, 1989.

[19] J. Szanyi, T. Medgyes, B. Kóbor, and M. Osvald, Conceptual Framework for Orebody-EGS: CHPM2030 Deliverable D1.4, Zenodo, 2016.

[20] J. Szanyi, M. Osvald, T. Medgyes et al., CHPM2030 Deliverable 2.1: Recommendations for Integrated Reservoir Management, Zenodo, 2017.

[21] A. Genter, N. Cuenot, B. Melchert et al., "Main achievements from the multi-well EGS Soultz project during geothermal exploitation from 2010 and 2012," in Proceedings European Geothermal Energy Congress, EGC 2013, Pisa, Italy, June 2013.

[22] E. Schill, A. Genter, N. Cuenot, and T. Kohl, "Hydraulic performance history at the Soultz EGS reservoirs from stimulation and long-term circulation tests," Geothermics, vol. 70, pp. 110-124, 2017. 

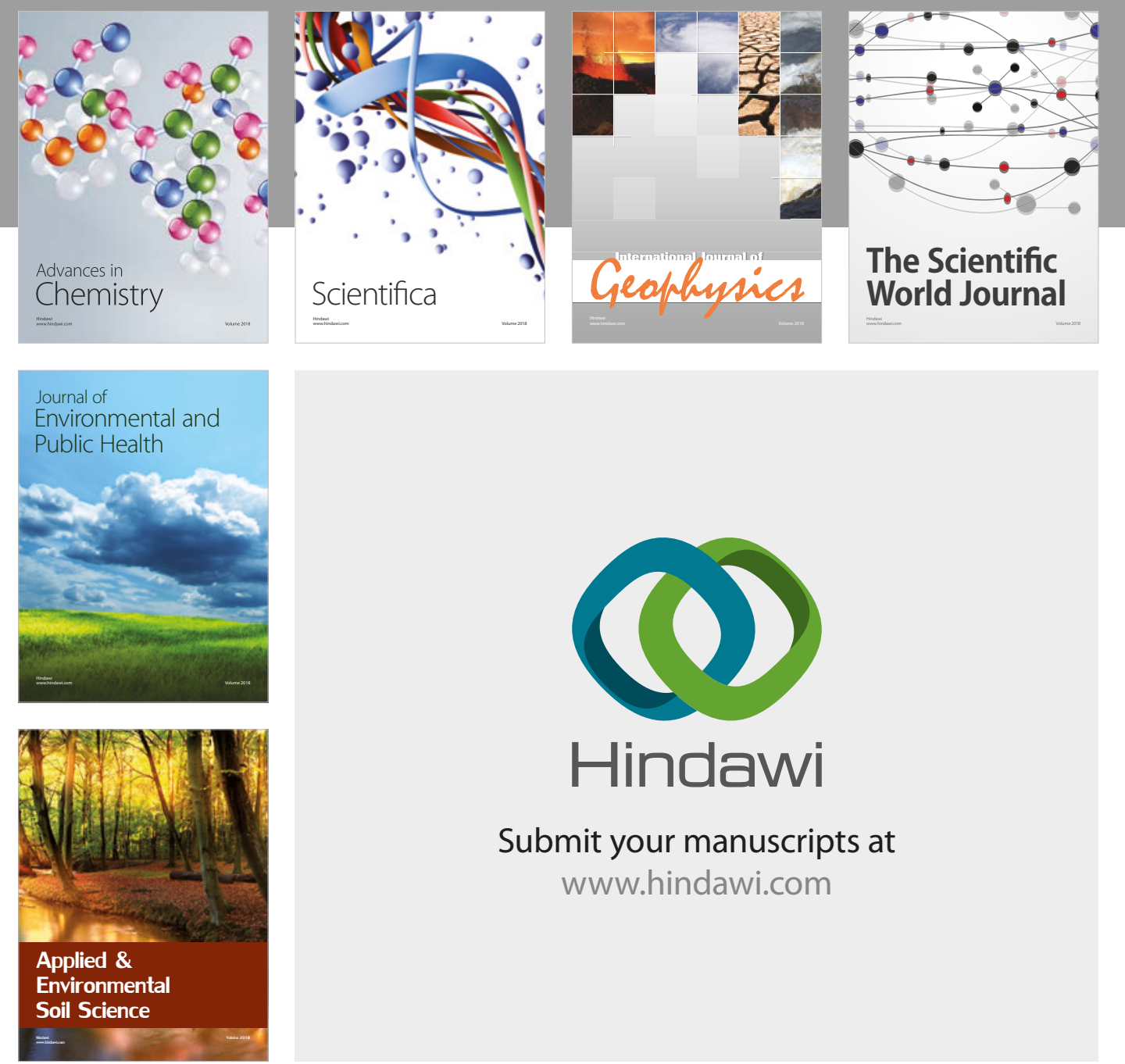

The Scientific

\section{World Journal}
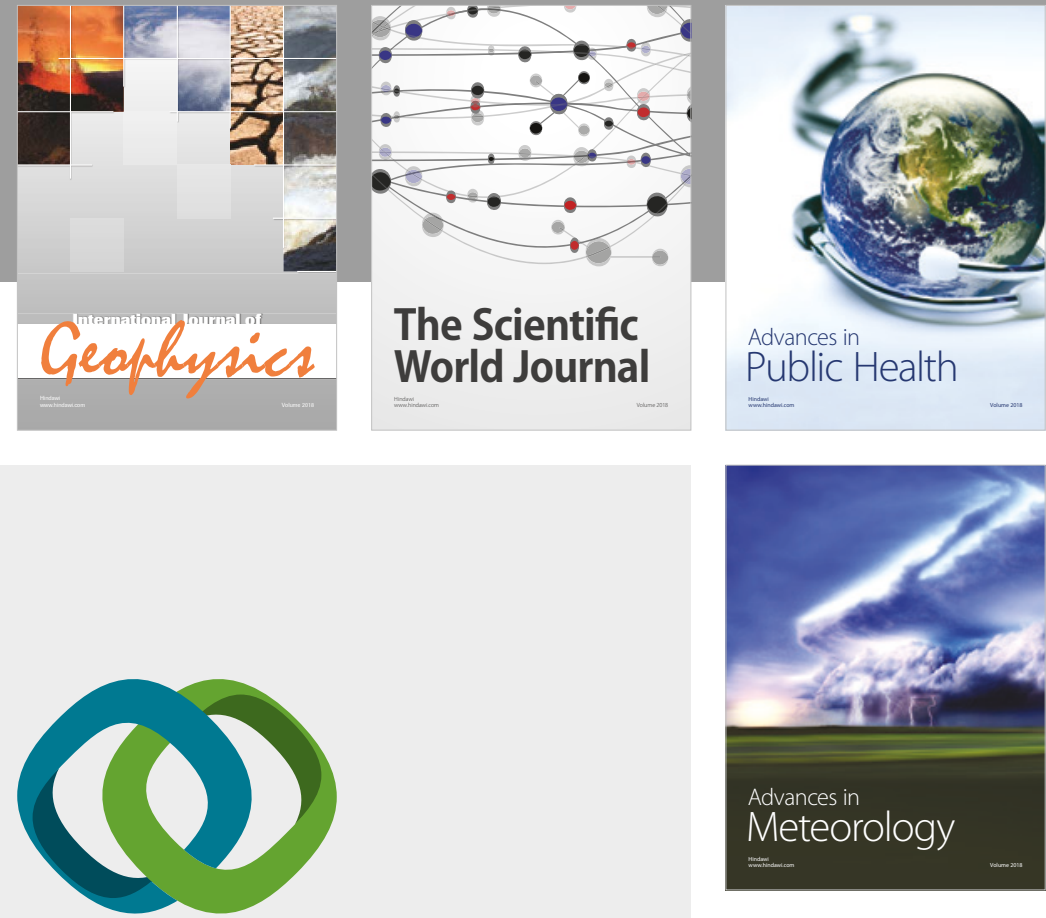

Advan

Public Health

\section{Hindawi}

Submit your manuscripts at

www.hindawi.com
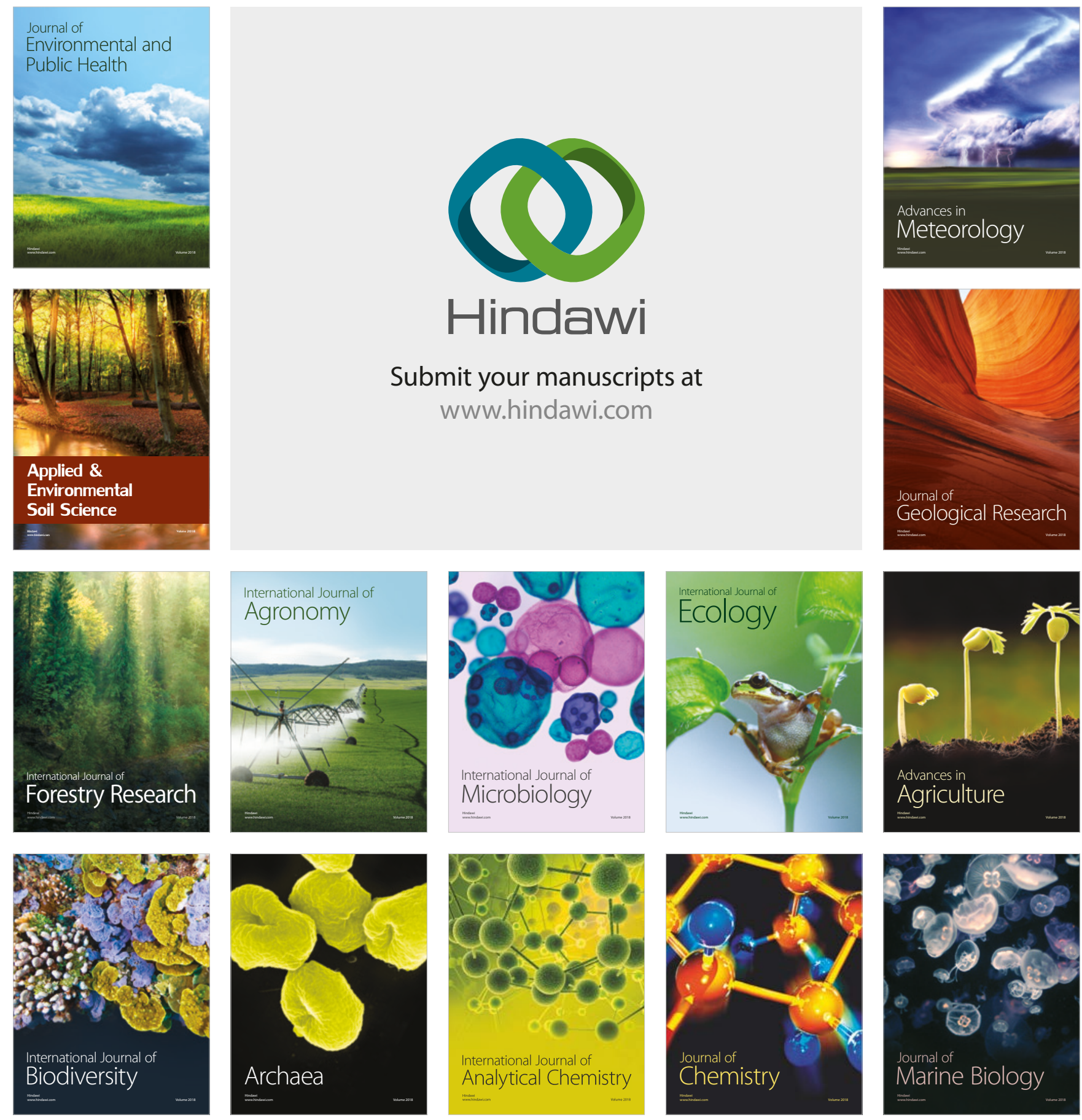